\title{
Age-related decrease in glucagon-like peptide-1 in mouse prefrontal cortex but not in hippocampus despite the preservation of its receptor
}

\author{
Ryo Ohshima ${ }^{1}$, Kanae Hotsumi ${ }^{1}$, Christian Holscher ${ }^{2}$, Kenjiro Seki ${ }^{1,}$ * \\ ${ }^{1}$ Department of Pharmacology, School of Pharmaceutical Science, Ohu University, 31-1 Misumido, Tomitamachi, Koriyama, Fukushima, \\ Japan \\ ${ }^{2}$ Division of Biomedical and Life Sciences, Faculty of Health and Medicine, Lancaster University, Lancaster LA1 4YQ, UK
}

\author{
Email address: \\ k-seki@pha.ohu-u.ac.jp (K. Seki)
}

\section{To cite this article:}

Ryo Ohshima, Kanae Hotsumi, Christian Holscher, Kenjiro Seki. Age-Related Decrease in Glucagon-Like Peptide-1 in Mouse Prefrontal Cortex but Not in Hippocampus Despite the Preservation of Its Receptor. American Journal of BioScience. Vol. 3, No. 1, 2015 , pp. 11-27. doi: 10.11648/j.ajbio.20150301.13

\begin{abstract}
Glucagon-like peptide-1 receptor (GLP-1R) agonist treatment has the potential to be a novel therapeutic treatment for Alzheimer's disease (AD). We previously reported that exendin-4, a Gas protein-coupled GLP-1R agonist, up-regulates the membrane AMPA receptor GluR1 subunit in the neocortex. However, it is uncertain whether GLP-1R agonists have an advantage as an $\mathrm{AD}$ treatment target compared with other Gas protein-coupled receptors. Here we show that both the protein level of proglucagon, a precursor of GLP-1, and the immunoreactivity level of GLP-1 are significantly decreased in the medial prefrontal cortex (mPFC) of aged mice (14 months old) compared with young ( 3 weeks old) or adult (6 months old) mice, but not in area CA1, the dentate gyrus (DG) nor in the nucleus of the solitary tract. However, the protein and immunoreactivity levels of GLP-1R in the mPFC, DG and hippocampal CA1 and CA3 areas were preserved in the aged mice. We then confirmed whether the age-dependent decrease in GLP-1 in the MPFC was associated with the activity level or the number of microglial cells in the mPFC. Co-staining of CD11b and GLP-1 in the MPFC revealed that the number of CD11b-positive cells was increased in the aged mice. Moreover, lipopolysaccharide (LPS) injection increased the number of CD11b-positive cells in the mPFC, but the number of GLP-1-positive cells was unchanged. However, the number of CD11b-positive cells that co-localized with GLP-1R in the $\mathrm{mPFC}$ is increased by LPS and aging. Because the GLP-1R is preserved in aged mPFC, but the amount of GLP-1 produced in the brain region is diminished, and spatial cognitive memory was impaired in aged mice, we propose that treatment with GLP-1 analogues has great promise for rescuing and ameliorating the age-related mPFC-dependent decline of cognitive functions.
\end{abstract}

Keywords: Glucagon-Like Peptide-1, Age-Related, Medial Prefrontal Cortex, Microglia, Alzheimer's Disease

\section{Introduction}

Reduced glucose utilization and energy metabolism occurs early in the course of Alzheimer's disease (AD) and correlates with impaired cognition. Growing evidence supports the hypothesis that $\mathrm{AD}$ is fundamentally a metabolic disease in which brain glucose utilization and energy production are impaired and responsiveness to insulin and insulin-like growth factor (IGF) stimulation [1]. The desensitization of insulin receptors in the brain has been observed in $\mathrm{AD}$ patients with Type 2 diabetes (T2DM) [2, 3]. Consistent with these observations, the restoration of insulin responsiveness and the use of insulin therapy can lead to improved cognitive performance [4], although with variable effects on the brain
Amyloid- $\beta$ protein precursor (A $\beta \mathrm{PP})-\mathrm{A} \beta$ load [5]. However, experimental evidence indicates that the toxic effects of A $\beta$ PP-A $\beta$ can promote insulin resistance [4].

Glucagon-like peptide-1 (GLP-1) stimulates insulin secretion and inhibits glucagon secretion in the pancreatic islets of Langerhans under hyperglycemic conditions. Liraglutide restores peripheral insulin sensitivity and reverse reduced basal levels of activated Akt and inhibited GSK-3 $\beta$ and tau hyperphosphorylation in brain of rats with T2DM [6]. Moreover, numerous preclinical studies targeting GLP-1 signaling for neuroprotective effects [7], anti-apoptotic activity [8], and ameliorating learning and cognition 
deficiencies [9, 10] have encouraged the re-purposing of anti-diabetics for the treatment of $\mathrm{AD}[11,12]$. The US FDA-approved anti-diabetic drugs exenatide and liraglutide are showing considerable promise in reducing $\mathrm{AD}$ pathology and in restoring normal brain insulin responsiveness and cognitive function in preclinical trials [13].

We previously reported that exendin-4, a potent agonist of the GLP-1 receptor (GLP-1R), promotes the up-regulation of the membrane AMPA receptor GluR1 subunit through the activation of cAMP response element-binding protein (CREB) and that this process occurs via Gas protein activation signaling in the mouse neocortex. Similar results were obtained with the intracerebroventricular administration of $A \beta$ oligomer [14]. Moreover, we have also demonstrated that GLP-1 analogue administration such as liraglutide consistently enhances long-term potentiation (LTP) and reverses the impairments of LTP that are induced by $\beta$-amyloid fragments in the CA1 area of the hippocampus [15]. It also reversed the loss of LTP observed in the APP/PS1 mouse model of AD and reduces the amyloid plaque load [16]. Consistent with these properties of GLP-1 receptor agonist on the synaptic plasticity, we previously demonstrated that the GLP-1 receptor knockout (Glp1r(-/-)) mice were impaired in the acquisition phase of a water maze task [17]. Moreover, Glp1r gene transfer restored the learning deficit in GLP-1R-deficient mice [18]. Therefore, intrinsic signaling via GLP-1R in brain is important for maintaining the ability of spatial learning and supporting cognitive functions.

G protein-coupled receptors (GPCRs), including the Gas, directly influence the amyloid cascade through the modulation of the $\alpha-, \beta$ - and $\gamma$-secretases, the proteolysis of the amyloid precursor protein (APP), and the regulation of amyloid- $\beta$ degradation [19]. Although it has been suggested that the GLP-1R is not only coupled to the Gas but also to the $\mathrm{G} \alpha \mathrm{i} / \mathrm{G} \alpha \mathrm{o}$ type of $\mathrm{G}$ proteins [20], our previous findings suggested that exendin-4 promotes the CREB phosphorylation-independent up-regulation of ADAM10 in the plasma membrane fraction of the mouse neocortex, resulting in the up-regulation of the protein level of the mature form of ADAM10, an $\alpha$-secretase of amyloid precursor protein (APP), indicating that the GLP-1R promotes the signaling pathway under the Gas protein in the mouse neocortex [14]. Additionally, the stimulation of Gas protein-coupled serotonin receptor 5-HT4 or pituitary adenylate cyclase-activating polypeptide type I receptor induced $\alpha$-secretase activation; the agonist of this receptor has been considered to be a therapeutic strategy for AD treatment $[21,22]$. Therefore, GLP-1 has beneficial properties for promoting the degradation of APP in addition to the enhancement of synaptic plasticity and cognition, which could partially contribute to the amelioration of insulin resistance as a treatment for $\mathrm{AD}$.

The GLP-1 acts as a growth factor in brain, and has been shown to induce neurite outgrowth and to protect against oxidative injury in cultured neuronal cells [23]. Because the nerve growth factor (NGF), leptin, brain-derived neurotrophic factor (BDNF) and insulin growth factor (IGF) are also neuroprotective [24-27], they have been investigated as possible AD treatments. Therefore, GLP-1 analogue also appear to be the choice for activating a Gas protein-coupled receptor and activating the second messenger growth factor signaling that may be useful in treating AD. However, it has not been reported that the expression levels of both GLP-1 and GLP-1R are affected by the aging regardless the A $\beta$ toxicity. Particularly, it is because that the age-related cognitive decline is induced in normal elderly persons in the absence of $A \beta$ toxicity in the brain $[28,29]$, therefore, in the present study, we aimed to clarify the age-dependent expression profiles of GLP-1 and GLP-1R in brain for elucidate the maximum benefit of GLP-1R agonist in brain functions.

\section{Materials and Methods}

\subsection{Chemicals and Antibodies}

Mouse monoclonal antibody, HYB 147-06 (sc-57166, 1:200) which was used for detecting the GLP-1 and proglucagon and rabbit polyclonal antibody against GLP-1R (H-55; sc-66911 1:50) were purchased from Santa Cruz Biotechnology, Inc. (Dallas, TX, USA) which qualities of these antibodies have already demonstrated [30-32]. Rabbit polyclonal antibody against GLP-1R (ab39071, 1:1,000) for Western blotting was purchased from Abcam plc (Cambridge, UK) which quality has previously demonstrated [33]. Rabbit polyclonal antibody against CD11b (NB110-89474, 1:100) was purchased from Novus Biologicals (Littleton, CO, USA). Lipopolysaccharide (L3129, serotype 0127:B8) was purchased from Sigma-Aldrich (St. Louis, MO, USA).

\subsection{Animal Ethics and Drug Applications}

This study was approved by the Animal Care Committee of Ohu University (No. 13-45). All animal procedures were performed in accordance with the guidelines of the Animal Care Committee of Ohu University. Special care was taken to reduce animal suffering and to use the minimum number of animals for all of the studies. Young CD1 mice (3-week-old males) were supplied by Charles River Laboratories Japan, Inc. (Yokohama, Japan). The adult and aged mice were grown to 6 and 14 months old respectively in the same environment with the young mice. All animals were housed at $25 \pm 2{ }^{\circ} \mathrm{C}$ on a 12-h:12-h light-dark schedule with ad libitum access to food and water. For the activation of the microglia cells in the mPFC, lipopolysaccharide (LPS; $1.0 \mathrm{mg} / \mathrm{kg}$ ) was administered via intraperitoneal injection (i.p.).

\subsection{Tissue Extraction and Western Blotting}

The mouse medial prefrontal cortex (mPFC), whole hippocampus and nucleus tractus solitarius (NTS) tissues section were quickly removed and Dounce-homogenized in RIPA buffer on ice. The RIPA buffer contained $50 \mathrm{mM}$ Tris-HCl (pH 7.0), 0.5 mM PMSF, $2.5 \mathrm{mM}$ EDTA, $2.5 \mathrm{mM}$ EGTA, $2.0 \mathrm{mM} \mathrm{Na} 3 \mathrm{VO} 4,100 \mathrm{mM} \mathrm{NaF}$, and 1:1,000 protease inhibitor cocktail (BioVision, Inc., Milpitas, CA, USA). Each extract was mixed with sample buffer containing $50 \mathrm{mM}$ 
Tris-HCl (pH 7.6), 2\% SDS, 10\% glycerol, $10 \mathrm{mM}$ dithiothreitol, and $0.2 \%$ bromophenol blue and boiled at $94^{\circ} \mathrm{C}$ for $5 \mathrm{~min}$. The boiled samples were electrophoresed in 8-14\% SDS-polyacrylamide gels, and the separated proteins were transferred onto PVDF membranes. The membranes were then incubated with primary antibodies that were detected using anti-rabbit or anti-mouse IgG conjugated to Western Lightning ECL (PerkinElmer, Inc., Waltham, MA, USA) for 1 $\mathrm{h}$ at room temperature and visualized using the VersaDoc imaging system (Model 5000; BioRad, Hercules, CA, USA). The protein bands were quantitatively analyzed using the ImageJ software (Version 1.48a, Wayne Rasband (NIH), Bethesda, MD, USA).

\subsection{Immunofluorescence}

The mice were transcardially perfused with ice-cold $0.1 \mathrm{M}$ phosphate-buffered saline (PBS) followed by filtered $4 \%$ paraformaldehyde in $0.1 \mathrm{M}$ PBS. For detecting the activating microglial cells, transcardial perfusion with ice-cold $0.1 \mathrm{M}$ PBS was performed at $2 \mathrm{~h}$ after the LPS injection. The brains were removed and post-fixed in $4 \%$ paraformaldehyde for 24 $\mathrm{h}$, followed by $30 \%$ sucrose at $4^{\circ} \mathrm{C}$ for at least $48 \mathrm{~h}$. Immunofluorescence was performed on $15-\mu \mathrm{m}$ coronal sections, and standard immunostaining techniques were employed. Each section was incubated for $30 \mathrm{~min}$ at $70^{\circ} \mathrm{C}$ using Histo VT ONE (Nacalai Tesque, Kyoto, Japan), which enhances the antigen reaction. The sections were incubated with the primary antibody overnight at $4{ }^{\circ} \mathrm{C}$ for histological analysis. TO-PRO-3 was used as a nucleus marker for cell counting and to confirm that the immunoflorescent objects seen were cell bodies. Anti-CD11b antibodies were used to detect the steady states of the microglia or activated microglia. A confocal scanning laser microscope (LSM 510, Carl Zeiss, Oberkochen, Germany) was used to detect and correct the fluorescence imaging data. Immunofluorescence was quantified using the Image Pro Plus (Media Cybernetics, Silver Spring, MD) imaging software. Positively labeled GLP-1- and CD11b-positive neurons were segmented using RGB intensity. Each brain section was imaged at $20 \times$ magnification for GLP-1 or GLP-1R with To-pro-3 in the CA1 or $\mathrm{CA} 3$ region of the hippocampus or the $\mathrm{mPFC}$ or NTS and $40 \times$ magnification for GLP-1 or GLP-1R and CD11b with TO-PRO-3 in mPFC. The data were analyzed using the Image J software to count the percentage of the GLP-1 or GLP-1Rand CD11b-positive cells relative to the number of TO-PRO-3 signals. We used three mice and obtained the three specimens from each mouse brain and acquired the triplicate images in individual area for representing the value as the total average of 9 images.

\subsection{Morris Water Maze Task}

The maze was made of white opaque plastic with a diameter of $120 \mathrm{~cm}$ and $40 \mathrm{~cm}$ high walls, and was filled with water at $25^{\circ} \mathrm{C}$ to avoid hypothermia. A small escape platform $(10 \times 6.5$ $\mathrm{x} 21.5 \mathrm{~cm}$ ) was placed at a fixed position in the centre of one quadrant, $25 \mathrm{~cm}$ from the perimeter, and was hidden $1 \mathrm{~cm}$ beneath the water surface. The room contained a number of fixed visual cued on the walls.

2.5.1. Acquisition phase: The acquisition trial phase consisted of 5 training days (Day 1-6) and four trials per day with a $15 \mathrm{~min}$ inter-trial interval. Four points equally spaced along the circumference of the pool (North, South, East, West) served as the starting position, which was randomised across the four trials each day. If an animal did not reach the platform within $90 \mathrm{~s}$, it was guided to the platform where it had to remain for $30 \mathrm{~s}$, before being returned to its home cage. Mice were kept dry, between trials, in a plastic holding cage filled with paper towels. The path length and escape latencies were recorded. Acquisition data, such as time taken to reach the escape platform and path length were analyzed by two-way repeated measures ANOVA.

2.5.2. Probe Trial: One day after finishing the acquisition task (Day 7), a probe trial was performed in order to assess the spatial memory (after a $24 \mathrm{~h}$ delay). The platform was removed from the maze and animals were allowed to swim freely for 60s. Spatial acuity was expressed as the amount of time spent in the exact area where the escape platform was located. The probe trial data was analyzed by one-way ANOVA, followed by Bonferroni's multiple comparison test. All groups were $\mathrm{n}=10$.

\subsection{Statistical Analysis}

Inter-group statistical comparisons were performed by a paired Student's or an unpaired t-test for pairwise comparisons of the means of two independent groups (control vs. exendin-4). For multiple comparisons, a one-way analysis of variance (ANOVA) was used with Bonferroni's correction as the post-hoc test. All statistical analyses were performed with StatView (Version 5.0, SAS Institute Inc., San Francisco, CA, USA) and ystat2002.xls (Igaku-Tosho, Tokyo, Japan) as appropriate. Behavioral data were analyzed by repeated measure two-way ANOVAS using PRISM (Graphpad software). All data in the bar graphs indicate the mean \pm the SEM. The levels of significance for all analyses were set at $\mathrm{p}<$ $0.05(*)$. N.S indicates that no significant difference was found between groups.

\section{Results}

\subsection{Age-Related Decreases in GLP-1 and Proglucagon in Aged MPFC but in Neither the Hippocampus nor NTS}

Proglucagon neurons that produce brain GLP-1 are located in the NTS. These neurons project widely to various regions in the brain and activate the central GLP-1 receptors [34]. However, outside of the NTS, microglial cells are the main source of GLP-1 in the cerebral cortex and the hippocampus, and proglucagon mRNA expression in these areas is significantly reduced in an obese insulin-resistant mouse model (Kappe et al., 2012). Because the activity of microglial cells is increased in aged mice (Perry et al., 1993), we investigated potential changes in the GLP-1 protein levels in the $\mathrm{mPFC}$, the hippocampus and the NTS of adults (6 months 
old) and aged mice. One-way ANOVA with the factor 'age' revealed that aging affected the protein level of the proglucagon, a precursor protein of GLP-1 in the mPFC, (Fig $1 \mathrm{~A}$ and $\mathrm{B}, \mathrm{F}(2,9)=10.964, \mathrm{p}=0.0039$, aged: $42.0 \pm 10.6 \%$ and adult: $97.0 \pm 10.4 \%$ that of young $\mathrm{mPFC}, \mathrm{n}=4$, respectively). Bonferroni post hoc test between individual groups indicated that there were significant differences between the young and the aged mice $(\mathrm{p}<0.0057, \mathrm{n}=4)$.
Consistent with this result, The GLP-1 protein signals in the mouse mPFC were detected via immunofluorescence analysis in both young and aged mice. However, the immunoreactivity of GLP-1 was significantly decreased in the aged mouse $\mathrm{mPFC}$ compared with the young mouse mPFC (Fig. $1 \mathrm{C}$ and D, young: $40.4 \pm 5.3 \mathrm{GLP}-1$-positive cells per 100 nuclei; aged: $15.1 \pm 3.6$ GLP-1 positive cells per 100 nuclei, $\mathrm{p}=0.0055, \mathrm{n}=$ 9 images from 3 mice, respectively).
A
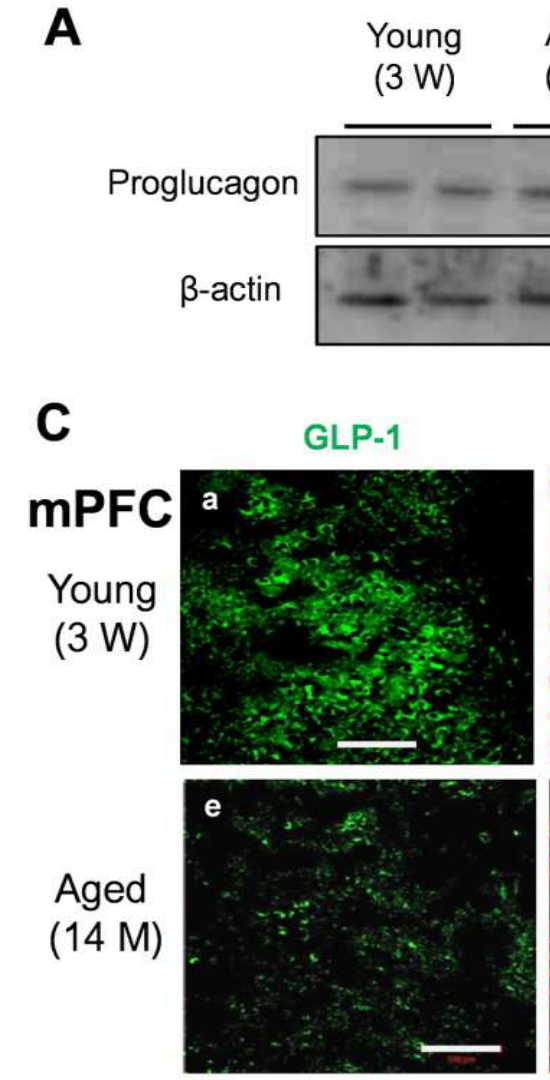

Aged
B

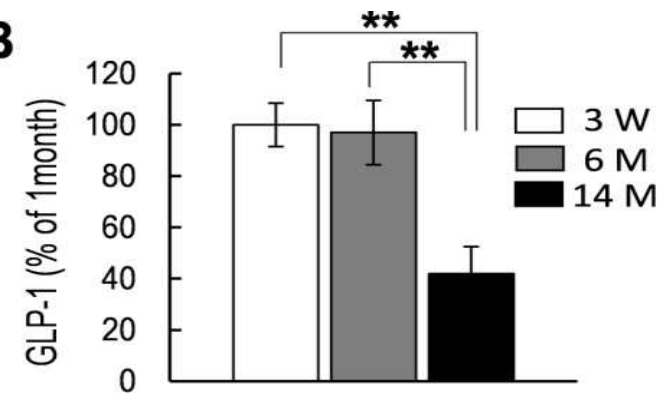

To-pro-3
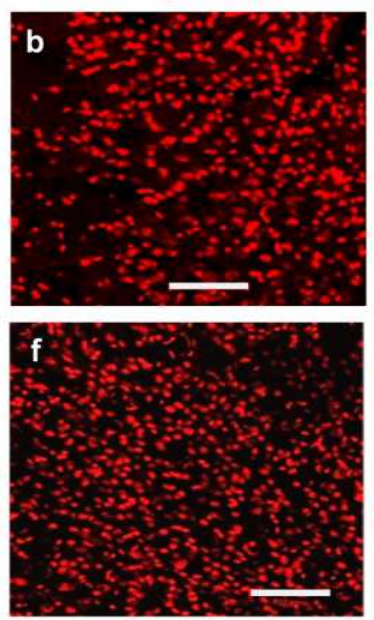

C (14 M)
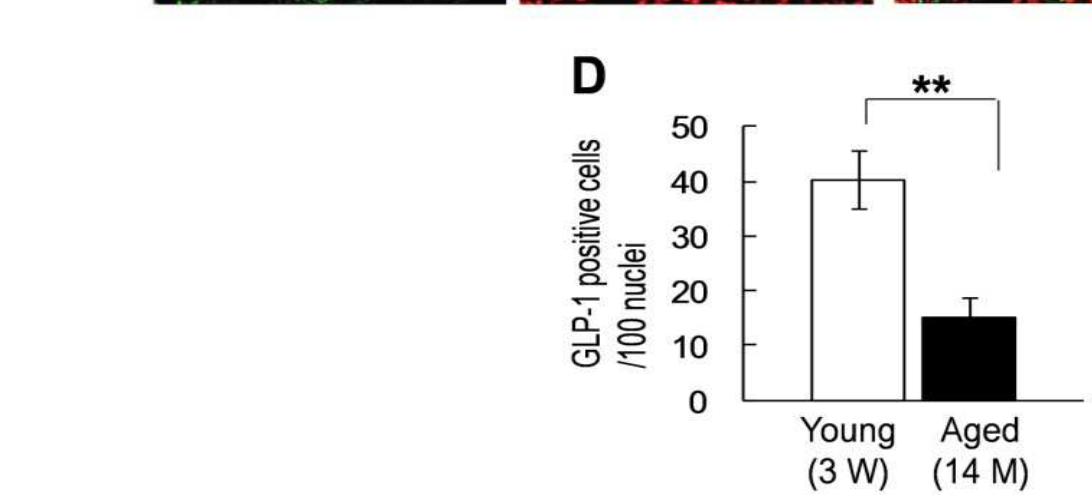

Merge
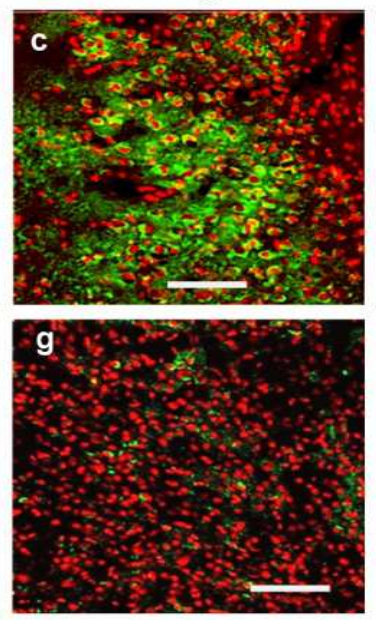


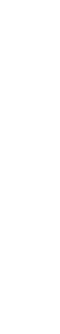

In contrast, GLP-1 immunoreactivity in the CA1 region of the hippocampus was preserved in aged mice compared with young mice (Fig. 2A and C, young: $23.0 \pm 2.8$ GLP-1 positive cells per 100 nuclei; aged: $26.4 \pm 5.6 \mathrm{GLP}-1$ positive cells per 100 nuclei, $\mathrm{p}=0.597, \mathrm{n}=9$ images from 3 mice, respectively). In the dentate gyrus (DG) of the hippocampus, GLP-1 immunoreactivity was also preserved in aged mice compared with young mice (Fig. 2B and C, young: $29.0 \pm 3.7$ GLP-1 positive cells per 100 nuclei; aged: $32.2 \pm 2.7$ GLP-1-positive cells per 100 nuclei, $\mathrm{p}=0.513, \mathrm{n}=9$ images from 3 mice, respectively). The protein level of proglucagon, a precursor protein of GLP-1 in the hippocampus, was consistently preserved in aged mice compared with young mice (Fig. 2D and $\mathrm{E}$, aged: $106.5 \pm 4.1 \%$ that of the young $\mathrm{mPFC}, \mathrm{p}=0.235$, $\mathrm{n}=4)$.

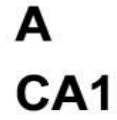

B

DG
Young
$(3 \mathrm{~W})$

$(14 \mathrm{M})$

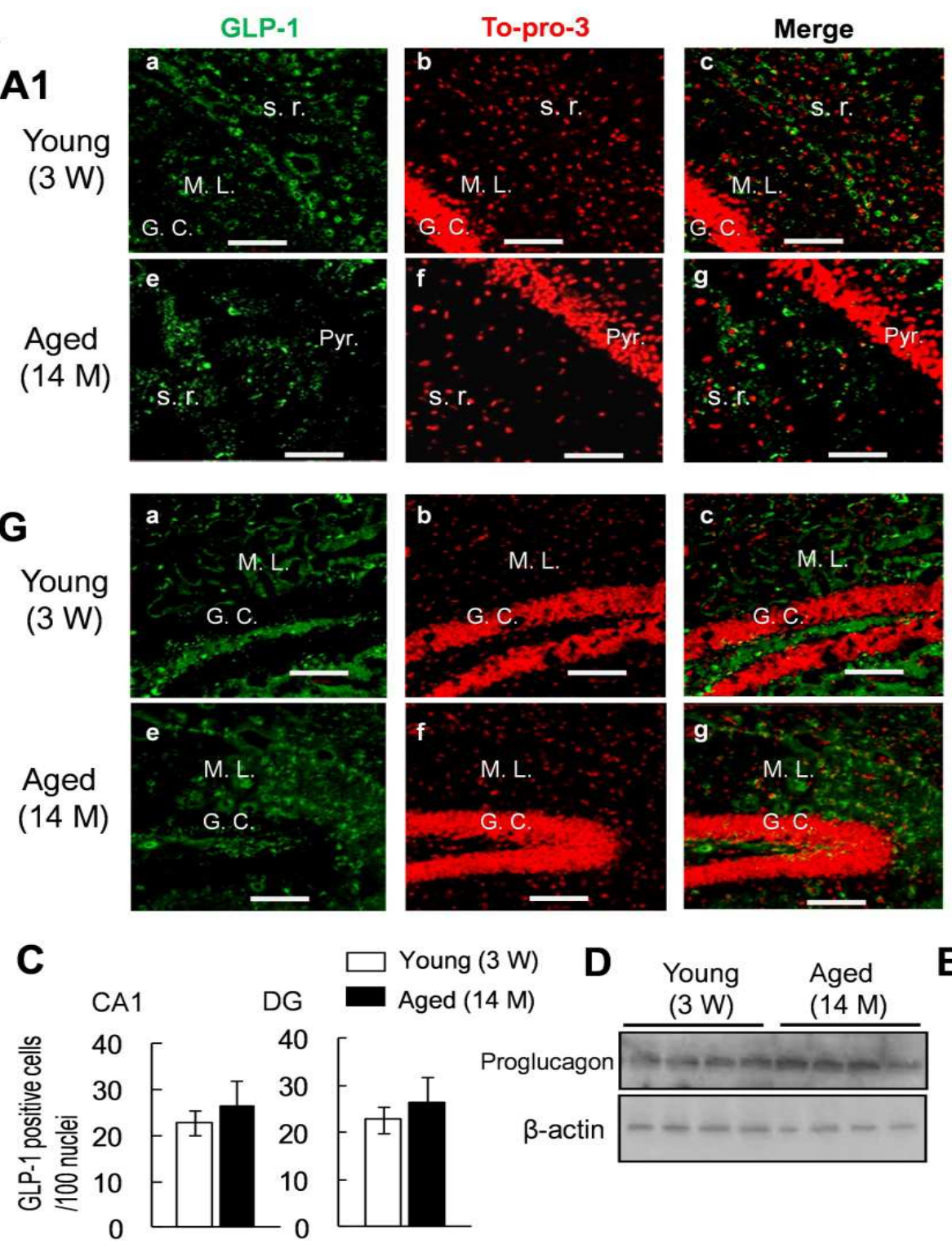
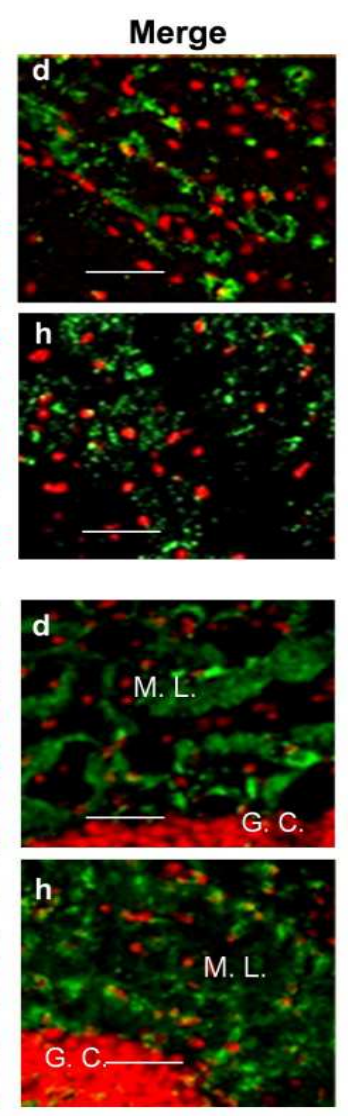

E Hippocampus

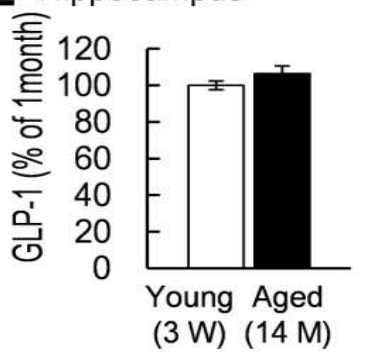

Figure 2. The immunoreactivity and protein levels of GLP-1 in both the CA1 region and DG of the hippocampus were preserved in aged mice.

A and B, Representative confocal images from the CA1 region (A) and DG area (B) of young (3-week-old, a-d) and aged mice (14-month-old, e-h) show the GLP-1-positive cells (green, a and e) and nuclear counterstaining with To-pro-3 (red, b and f). The merged image shows that GLP-1 is mainly expressed in the stratum radiatum (s.r.) (A) and in the molecular layer (M.L.) (B). The thick bar in each panel represents $100 \mu \mathrm{m}$ (a-c and e-g). The right panels show the enlarged images from the middle right panel as merged images ( $\mathrm{d}$ and $\mathrm{h}$, scale bar: $40 \mu \mathrm{m}$ ). C, The bar graph indicates the rate of the number of GLP-1-positive cells against 100 nuclei. The numbers of GLP-1-positive cells in the CA1 region (left) and the DG area (right) of aged mice were not significantly different from those of young mice. The bars represent the means \pm SEM ( $n=9$ images from 3 mice). D and E, Western blotting (D) and quantitative analysis (E) from the whole hippocampal extraction of young (open bars, $n=4$ ) and aged mice (closed bars, $n=4$ ) revealed that the total protein levels of GLP-1 in the hippocampus of the aged mice were preserved compared with those of the young mice (D). The data are expressed as the percentage of young mice. Quantitative values from each band for pro-GLP-1 were normalized using the $\beta$-actin expression level. 
Moreover, immunofluorescence images revealed that GLP-1 in the NTS was also preserved in aged mice compared with young mice (Fig. 3A and B, young: $18.6 \pm 3.0$ GLP-1 positive cells per 100 nuclei; aged; $21.4 \pm 1.6$ GLP-1 positive cells per 100 nuclei, $\mathrm{p}=0.4317, \mathrm{n}=9$ images from 3 mice, respectively). The protein levels of proglucagon, a precursor protein of GLP-1 in the NTS, were also consistently preserved in aged mice compared with young mice (Fig. $3 \mathrm{C}$ and D, aged: $91.5 \pm 4.9 \%$ that of the young mPFC, $p=0.4619, n=4)$. From these results, it is evident that GLP-1 is poorly functional in the mPFC of aged mice, but in the hippocampus and the NTS, GLP-1 remains functional even in aged mice.
A

\section{NTS}

Young $(3 \mathrm{~W})$
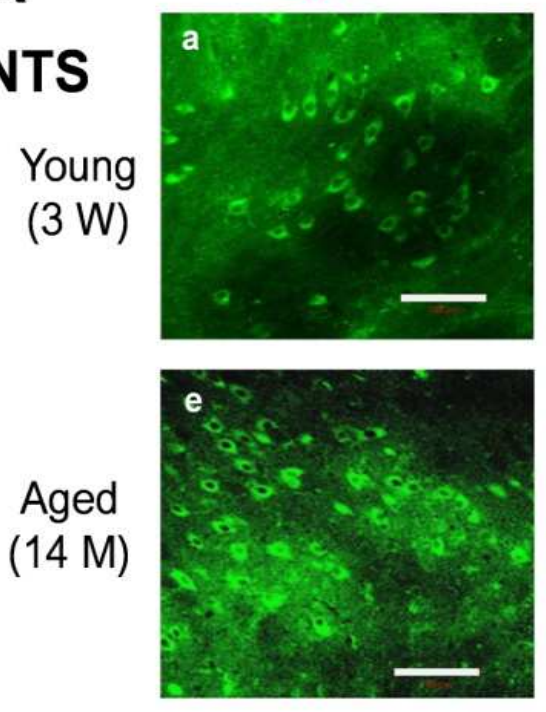

B

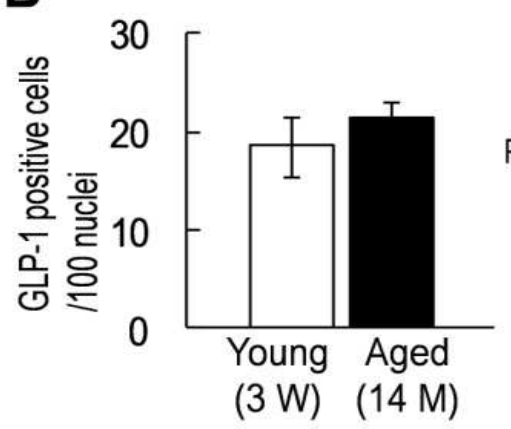

To-pro-3
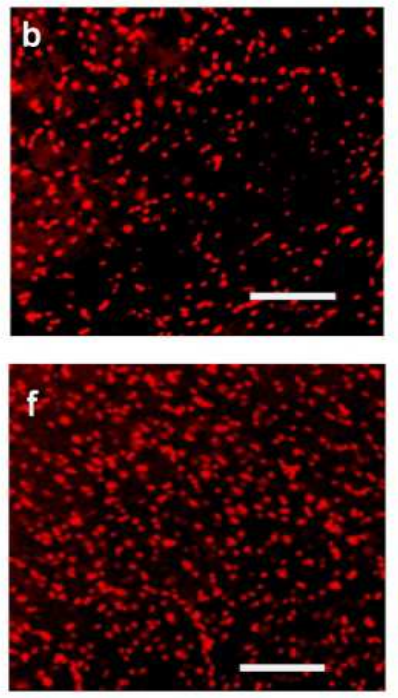

C

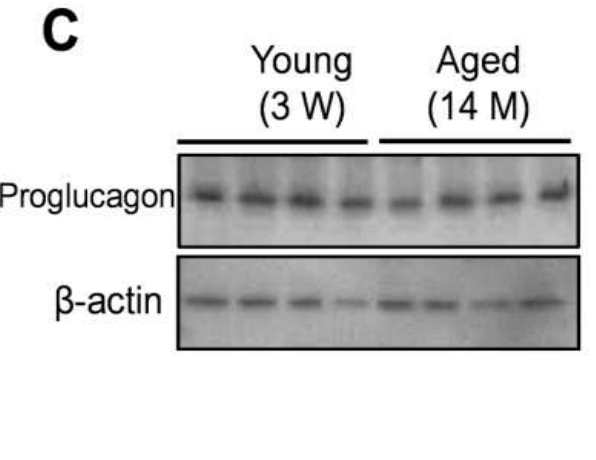

Merge

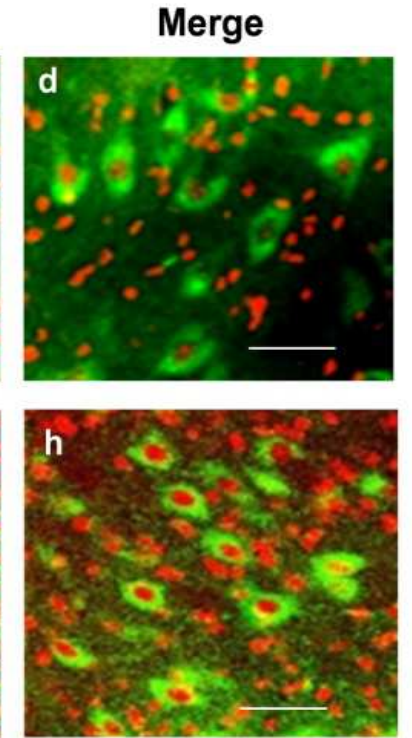

D

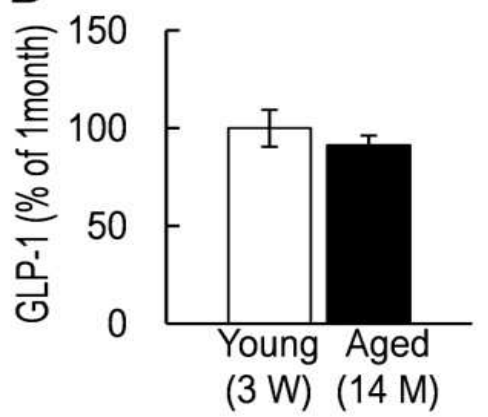

Figure 3. The protein level and immunoreactivity of GLP-1 were normal in the aged NTS.

A, Representative confocal images from the NTS of young mice (3 weeks old, a-d) and aged mice (14 months old, e-h) show the GLP-1-positive cells (green, a and e) and nuclear counterstaining with To-pro-3 (red, b and f). The merged image shows that GLP-1 was expressed around the nucleus (c and g). The thick bar in each panel represents $100 \mu \mathrm{m}$ (a-c and e-g). The panels showing in $\mathrm{d}$ and $\mathrm{h}$, indicating the enlarged images from the images showing in $\mathrm{c}$ and $\mathrm{g}$ as merged images (Scale bar: $40 \mu \mathrm{m}$ ). B, The bar graph indicates the proportion of GLP-1-positive cells out of 100 nuclei. The number of GLP-1-positive cells in the NTS of aged mice was not significantly different from that of the young mice. The bars represent the means \pm SEM ( $n=9$ images from 3 mice). C and D, Western blotting (C) and quantitative analysis (D) from the NTS of young (open bars, $n=4$ ) and aged mice (closed bars, $n=4$ ) revealed that the protein level of GLP-1 in the NTS was preserved in the aged mice compared with the young mice (D). The data are expressed as the percentage of young mice. Quantitative values from each band for pro-GLP-1 were normalized using the $\beta$-actin expression level.

\subsection{GLP-1R in Aged Mice is Preserved in the MPF and Hippocampus}

Before implementing a GLP-1 analogue in the treatment of $\mathrm{AD}$, it is important to determine whether the normal protein level of GLP-1R in the mPFC is preserved in aged mice. Therefore, we performed immunofluorescence and western blotting to detect GLP-1R in the MPFC and the hippocampus. Although the GLP-1 in the aged mice was significantly decreased in the mPFC, the GLP-1R immunoreactivity in the $\mathrm{mPFC}$ was at normal levels in the aged mice compared with the young mice (Fig. 4A and B, young: $31.7 \pm 6.9$ GLP-1R-positive cells per 100 nuclei; aged: $33.8 \pm 6.5$ GLP-1R-positive cells per 100 nuclei, $\mathrm{p}=0.8286, \mathrm{n}=9$ images from 3 mice, respectively). Additionally, western blotting analysis revealed that normal protein levels of GLP-1R in the mPFC were also preserved in the aged mice compared with the young mice (Fig. 4C and D, aged: $103.5 \pm$ 
$3.0 \%$ that of the young mPFC, $\mathrm{p}=0.1997, \mathrm{n}=4$ ).

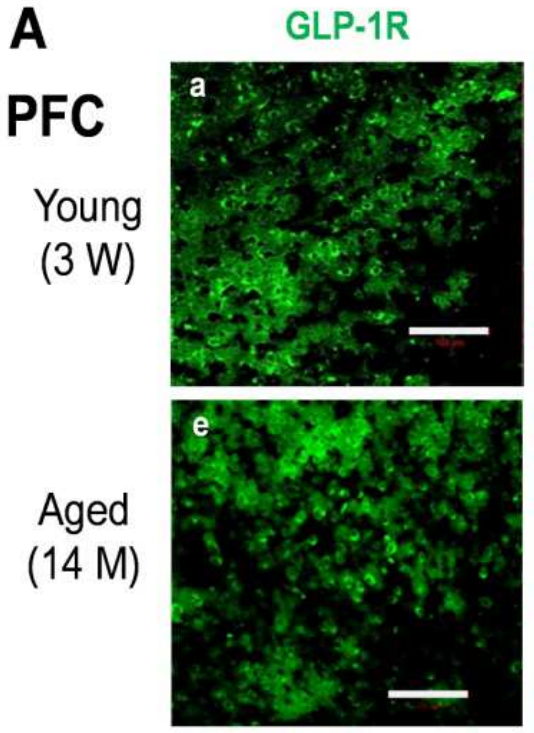

B

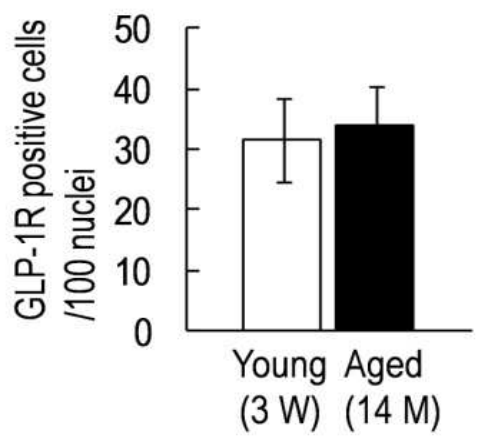

To-pro-3
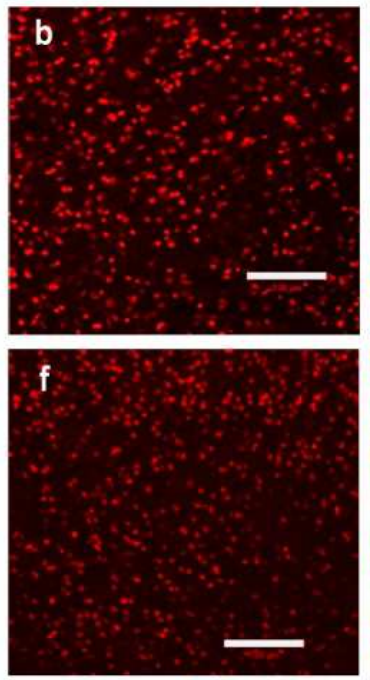

C
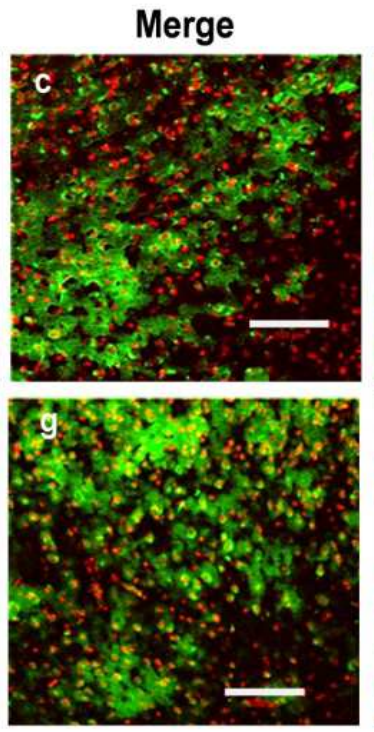
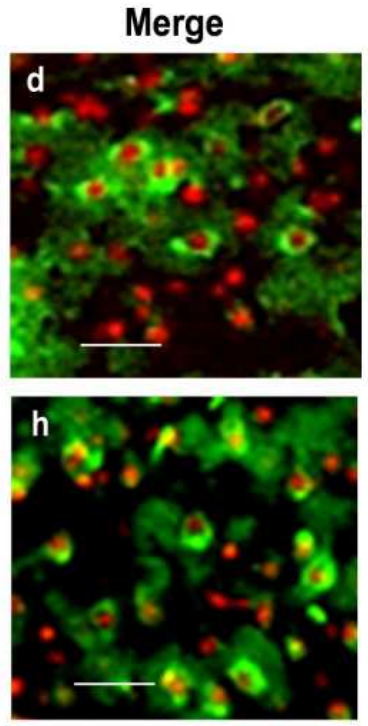

\section{D}

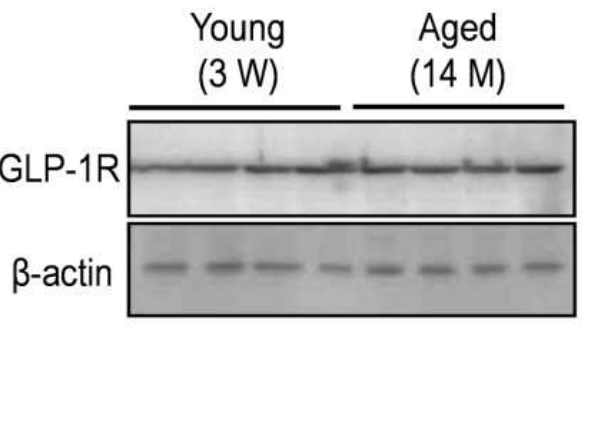

Figure 4. The protein level and immunoreactivity of GLP-1R were normal in the aged $m P F C$.

A, Representative confocal images from the mPFC of young (3-week-old, top) and aged (14-month-old, bottom) mice show the GLP-1R-positive cells (green, left panel) and nuclear counterstaining with To-pro-3 (red, middle left panel). A merged image shows that GLP-1R is expressed around the nucleus (indicated with red To-pro-3 staining, middle right panel). The thick bar in each panel represents $100 \mu \mathrm{m}$ (left, middle left, and middle right panels). The panels showing in $\mathrm{d}$ and $\mathrm{h}$, indicating the enlarged images from the images showing in $\mathrm{c}$ and $\mathrm{g}$ as merged images (Scale bar: $40 \mu \mathrm{m}$ ). B, The bar graph indicates the proportion of GLP-1R-positive cells out of 100 nuclei. The number of GLP-1R-positive cells in the mPFC of the aged mice was not significantly different from that of the young mice. The bars represent the means \pm SEM $(n=9$ images from 3 mice). C and $D$, Western blotting (C) and quantitative analysis (D) from the mPFC of young (open bars, $n=4$ ) and aged mice (closed bars, $n=4$ ) revealed that the protein level of GLP-1R in the mPFC was preserved in the aged mice compared with the young mice (D). The data are expressed as the percentage of young mice. The quantitative value from each band for GLP-1R was normalized using the $\beta$-actin expression level.

To further confirm the detailed localization and the protein levels of GLP-1R in the hippocampus, we performed immunofluorescence analysis on three areas within the hippocampus. In the CA1 region, GLP-1R was highly expressed on the pyramidal neuron and somewhat expressed on the non-pyramidal cells around the pyramidal layer. The GLP-1R immunoreactivity in the CA1 region of the aged mice remained at normal levels compared with the young mice (Pyramidal neurons: Fig. 5A and 6A, young: $88.1 \pm 3.5$ GLP-1R-positive cells per 100 nuclei; aged: $89.1 \pm 3.1$ GLP-1R positive cells per 100 nuclei, $\mathrm{p}=0.8288, \mathrm{n}=9$ images from 3 mice, respectively. Non-pyramidal cells: Fig. 5A and $6 \mathrm{~B}$, young: $18.3 \pm 1.7 \mathrm{GLP}-1 \mathrm{R}$-positive cells per 100 nuclei; aged: $16.7 \pm 1.3$ GLP-1R-positive cells per 100 nuclei, $\mathrm{p}=$
$0.4661, \mathrm{n}=9$ images from 3 mice, respectively). In the DG of the hippocampus, GLP-1R was mainly expressed on the granule cells but at lower levels than in CA1. The GLP-1R immunoreactivity in the DG of aged mice also remained at a normal level compared with the young mice (Fig. 5B and 6C, young: $28.1 \pm 6.5$ GLP-1R-positive cells per 100 nuclei; aged: $26.2 \pm 5.1$ GLP-1R-positive cells per 100 nuclei, $\mathrm{p}=0.7488, \mathrm{n}$ $=9$ images from 3 mice, respectively). Furthermore, as observed in the CA1 region, GLP-1R was highly expressed on the pyramidal neurons in the CA3 region; the GLP-1R immunoreactivity in the $\mathrm{CA} 3$ region of the aged mice also remained at normal levels compared with the young mice (Fig. 5C and $6 \mathrm{D}$, young: $87.9 \pm 2.5$ GLP-1R-positive cells per 100 nuclei; aged: $89.0 \pm 2.0 \mathrm{GLP}-1 \mathrm{R}$-positive cells per 100 nuclei, 
$\mathrm{p}=0.7325, \mathrm{n}=9$ images from 3 mice, respectively).

A
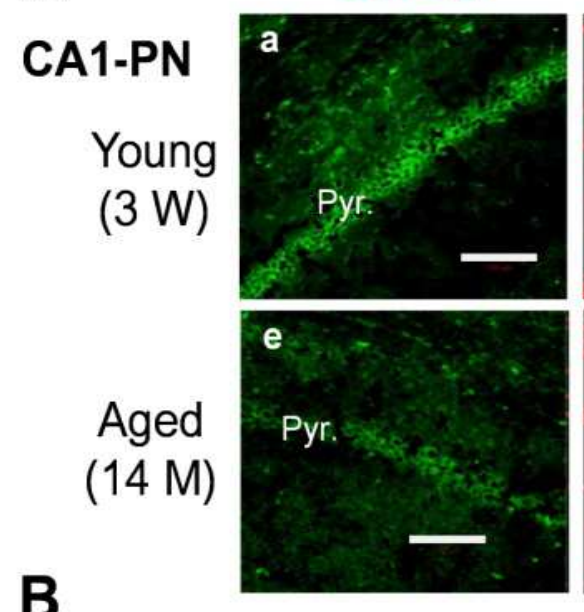

B
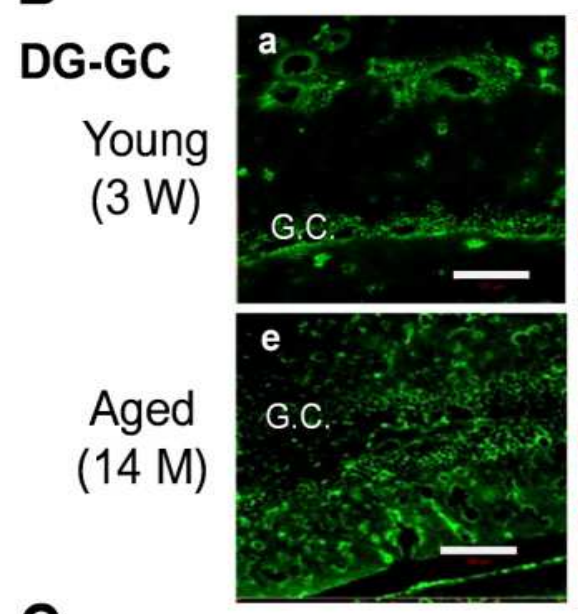

C

\section{CA3-PN \\ Young \\ $(3 \mathrm{~W})$}
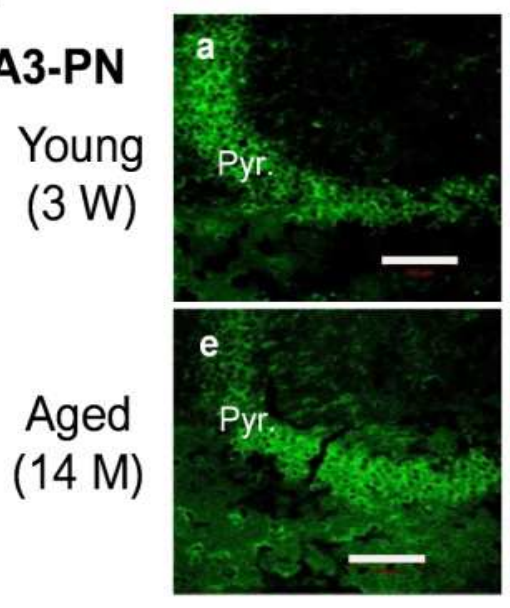

To-pro-3


Merge
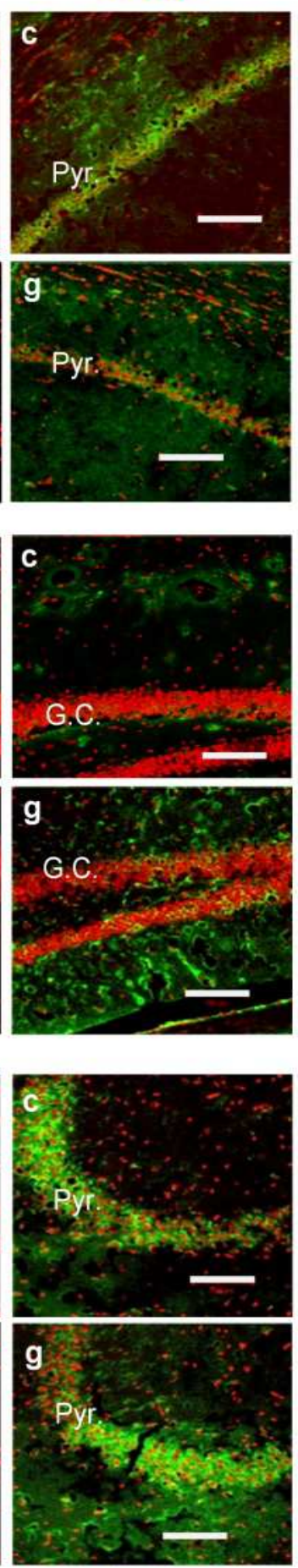

Merge
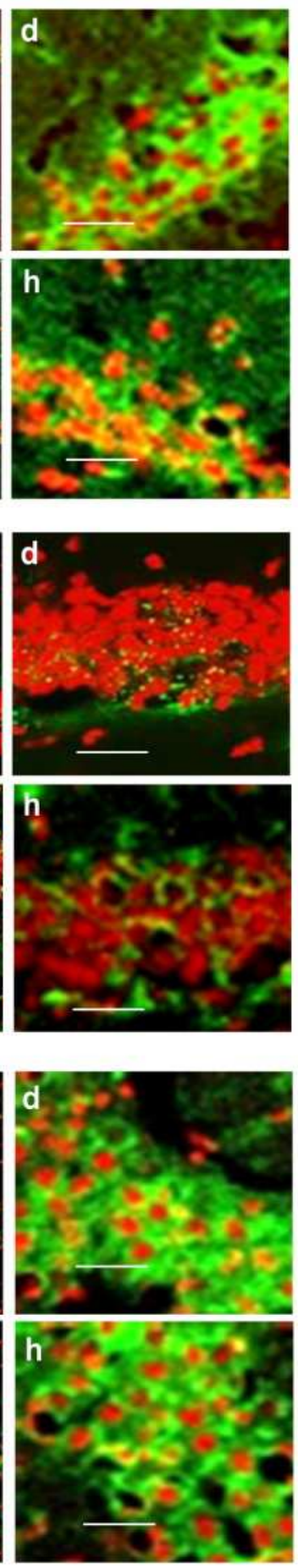

Figure 5. Protein level and immunoreactivity of GLP-1R in the aged hippocampus.

A-C, Representative confocal images from the CA1 region (A), the DG area (B) and the CA3 region (C) of young (3-week-old, a-d) and aged mice (14-month-old, e-h) show GLP-1R-positive cells (green, a and e) and nuclear counterstaining with To-pro-3 (red, b and f). Merged images show that GLP-1R was primarily expressed near the pyramidal neurons (Pyr.) (A), granule cells (G.C.) (B) and pyramidal neurons (C). The thick bar in each panel represents $100 \mu \mathrm{m}$ (a-c and e-g). The panels showing in $\mathrm{d}$ and $\mathrm{h}$, indicating the enlarged images from the images showing in $\mathrm{c}$ and $\mathrm{g}$ as merged images (Scale bar: $40 \mu \mathrm{m}$ ).

Additionally, western blotting analysis revealed that normal protein levels of GLP-1R in the hippocampus were also preserved in the aged mice compared with the young mice
(Fig. 6E and F, aged: $108.5 \pm 3.0 \%$ that of the young hippocampus, $\mathrm{p}=0.0908, \mathrm{n}=4$ ). These data demonstrate that the protein levels of both GLP-1 and GLP-1R are preserved in 
the hippocampus of aged mice.

A
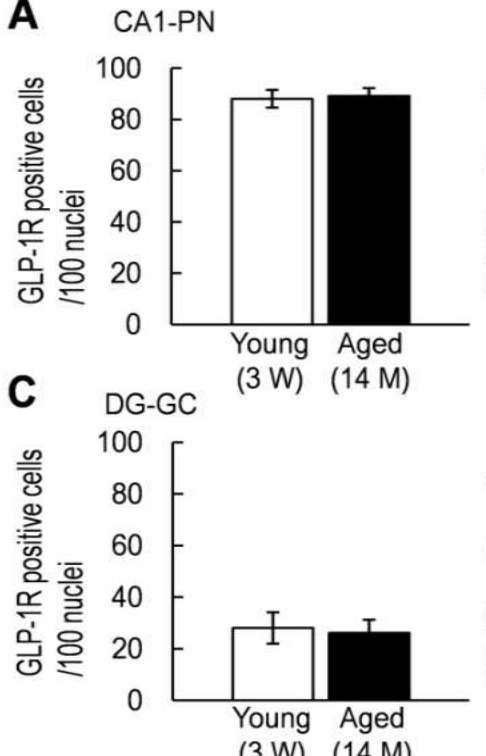

(3 W) (14 M)
B CA1-non PN

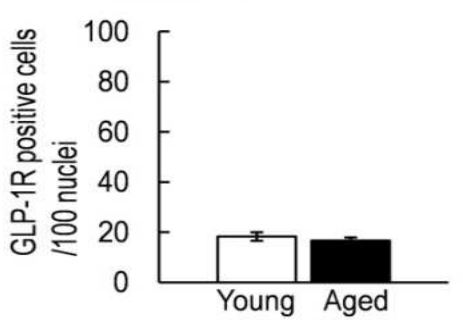

D CA3-PN $^{(3 \mathrm{~W})}(14 \mathrm{M})$

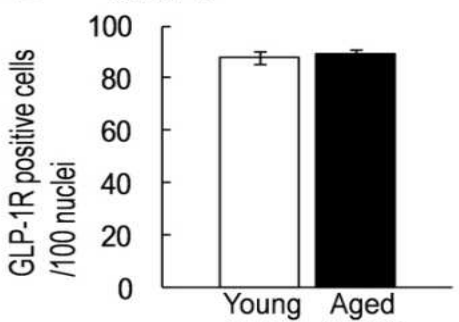

(3 W) (14 M)

F Hippocampus


(3 W) (14 M)

Figure 6. Analysis of the protein level and immunoreactivity of GLP-1R in the aged hippocampus.

A-D, The bar graphs indicate the rate of the number of GLP-1R-positive cells against 100 nuclei. The number of GLP-1R-positive pyramidal neurons in the CA1 region (A), non-pyramidal neurons in the CA1 region (B), granule cells in the DG area (C) and pyramidal neurons in the CA3 region of the aged mice (14-month-old) were not significantly different from the young (3-week-old) mice, respectively. The immunoreactivity levels of GLP-1R in the DG area of both the young and aged mice were lower than those in the CA1 and CA3 regions. The bars represent the means \pm SEM ( $\mathrm{n}=9$ images from 3 mice). E and F, Western blotting (E) and quantitative analysis (F) from the hippocampus of young (open bars, $n=4$ ) and aged mice (closed bars, $n=4$ ) revealed that the protein levels of GLP-1R in hippocampus were preserved in the aged mice compared with the young mice (F). The data are expressed as the percentage of young mice. Quantitative values from each band for GLP-1R were normalized using the $\beta$-actin expression level.

\subsection{Decreased GLP-1 Levels in the Aged MPFC is not Associated with the Number of Activated Microglial Cells}

GLP-1 is produced in the NTS and activates the dorsomedial hypothalamic neurons [32]. However, because GLP-1 is co-localized with cluster of differentiation molecule 11B (CD11b), a microglial marker [35, 36], and is lacking in neurons outside the NTS [37], the main source of GLP-1 in the cerebral cortex is microglial cells. Microglial cells provide several macrophage-related activities and play a pivotal role in the immune system in the brain [38]. CD11b is known to be age-dependently increased [39]. In the present study, the GLP-1 in the aged mPFC was significantly decreased compared with that in the young mice. Therefore, we confirmed the localization of GLP-1 and CD11b in the mPFC. This confirmation was required for us to investigate whether the GLP-1 expression level in the mPFC was associated with the number of activated microglial cells. The number of GLP-1-positive cells was $38.3 \pm 5.8$ in the young mice and $12.0 \pm 1.6$ in the aged mice (Fig. 7A, B and C, $\mathrm{p}=0.00838, \mathrm{n}=$ 9 images from 3 mice, respectively). However, the number of CD11b-positive cells in the aged mice was significantly larger than in the young mice (Fig. 7A, B and D, young: $51.8 \pm 2.7$; aged: $74.8 \pm 6.1, \mathrm{p}=0.0152, \mathrm{n}=9$ images from 3 mice, respectively). Although there were many more CD11b-positive cells than GLP-1-positive cells in the young mice, most of the GLP-1-positive cells co-expressed CD11b in both the young and aged mice under normal conditions (Fig. 7F, young: $87.0 \pm 16.7 \%$; aged: $95.8 \pm 16.8 \%, \mathrm{n}=9$ images from 3 mice, respectively). To investigate whether GLP-1 expression was associated with the activity level of the microglial cells in the $\mathrm{mPFC}$, we injected both young and aged mice with $1 \mathrm{mg} / \mathrm{kg}$ of LPS (i.p.). The LPS injection significantly increased the number of CD11b-positive cells in 
the young mice (Fig. 7A and D, naïve: $51.8 \pm 2$; LPS: $74.6 \pm$ $5.0, \mathrm{p}=0.0065, \mathrm{n}=9$ images from 3 mice, respectively). However, the number of GLP-1-positive cells in the young mPFC was not changed by the LPS injection (Fig. 7A and C, naïve: $38.3 \pm 5.8$; LPS: $36.3 \pm 3.2, \mathrm{p}=0.7674, \mathrm{n}=9$ images from 3 mice, respectively). Although the number of CD11b-positive cells in the young mice was increased via LPS treatment, the number of cells that co-expressed GLP-1 and CD11b was not changed by the LPS injection (Fig. 7E, naïve: $30.5 \pm 3.3$; LPS: $25.3 \pm 0.9, \mathrm{p}=0.1989, \mathrm{n}=9$ images from 3 mice, respectively), indicating that only the number of CD11b-positive cells that did not express GLP-1 was increased by the LPS injection, and the GLP-1 expression level was not associated with the activity level in the microglial cells. However, the number of CD11b-positive cells was already increased in the naive aged mPFC compared with the young $\mathrm{mPFC}$; thus, the LPS injection did not affect the number of CD11b-positive cells in the aged mPFC (Fig. $7 \mathrm{~B}$ and $\mathrm{F}$, naïve: $74.8 \pm 6.1$; LPS: $80.3 \pm 4.4, \mathrm{p}=0.4850, \mathrm{n}=9$ images from 3 mice, respectively). Additionally, the number of cells that co-expressed GLP-1 and CD11b in the aged mPFC was not changed by LPS treatment (Fig. 7E, naïve: 10.5 \pm 0.9 ; LPS: $8.7 \pm 1.5, \mathrm{p}=0.3575, \mathrm{n}=9$ images from 3 mice, respectively). These results suggest that the age-related decrease in GLP-1 expression in the mPFC depends on neither the number nor the activity level of the microglial cells.

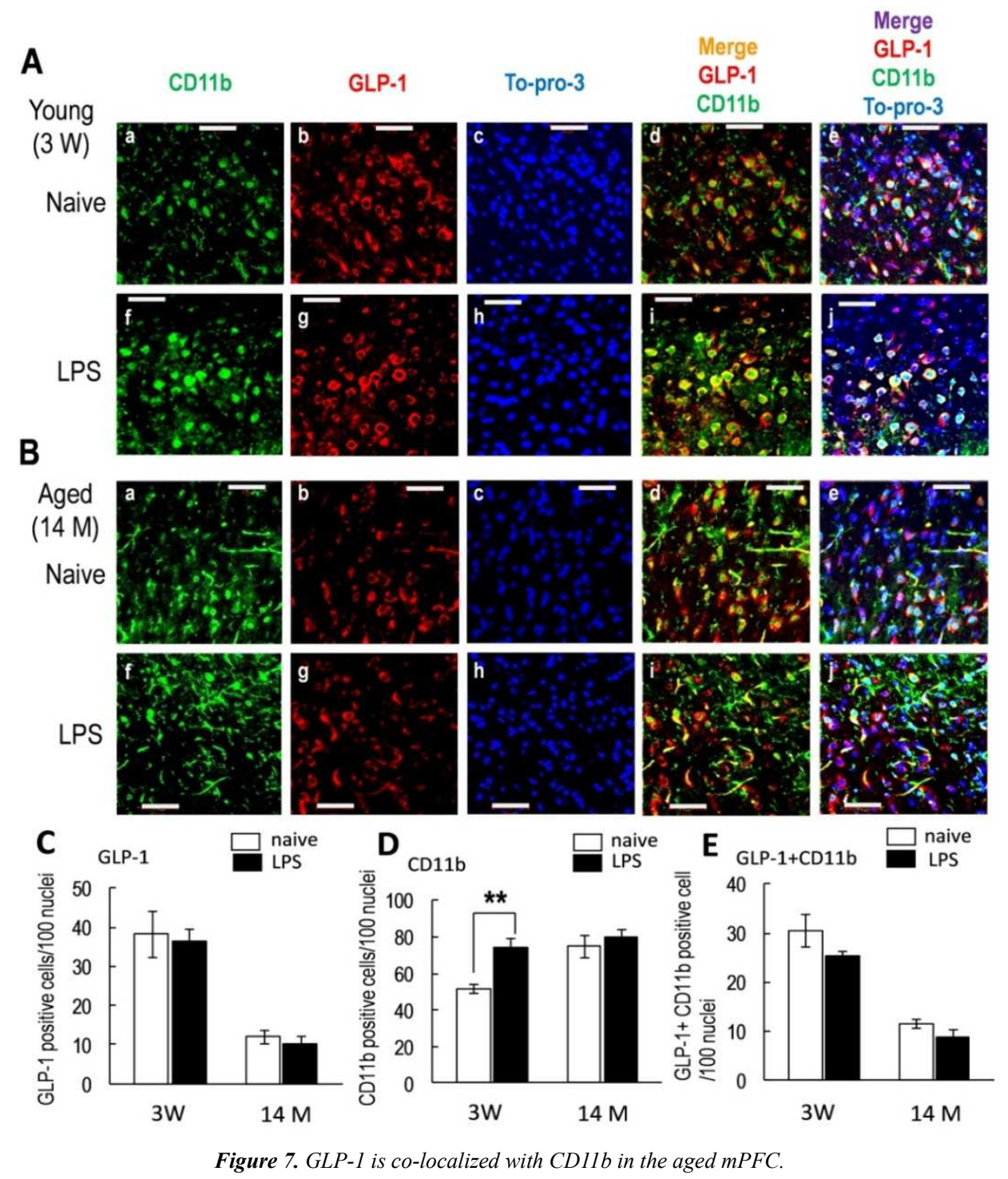

A and B, Representative confocal images from the mPFC of young (3-week-old) and aged (14-month-old) naïve (a-e) and LPS-treated mice (f-j) showing GLP-1-positive cells (green, a and f), CD11b-positive cells (red, b and g) and nuclear counterstaining with To-pro-3 (blue, c and h). The thick bar in each panel represents $50 \mu \mathrm{m}$. C, The bar graphs indicate the rate of the number of GLP-1-positive cells against 100 nuclei in the mPFC of naïve (open bar) and LPS-treated (closed bar) young and aged mice. The number of GLP1-positive cells in the mPFC of both the young and aged mice was not changed by LPS. D, The bar graphs indicate the proportion of CD11b-positive cells out of 100 nuclei in the mPFC of naïve (open bar) and LPS-treated (closed bar) young and aged mice. The number of CD11b-positive cells in the young mPFC was increased by LPS; this effect did not occur in the aged mice. E, The bar graphs indicate the number of CD11b-positive cells that co-localized with GLP-1 in the mPFC of naïve (open bars) and LPS-treated (closed bars) young and aged mice. The bars represent the means \pm SEM ( $\mathrm{n}=9$ images from 3 mice). 




Figure 8. The number of double-labelled GLP-1R and CD11b cells are increased by LPS in the mPFC.

A and B, Representative confocal images from the mPFC of young (3-week-old) and aged (14-month-old) naïve (a-e) and LPS-treated mice (f-j) showing GLP-1-positive cells (green, a and f), CD11b-positive cells (red, b and g) and nuclear counterstaining with To-pro-3 (blue, $\mathrm{c}$ and h). The thick bar in each panel represents $50 \mu \mathrm{m}$. C, The bar graphs indicate the rate of the number of GLP-1R-positive cells against 100 nuclei in the mPFC of naïve (open bar) and LPS-treated (closed bar) young and aged mice. The number of GLP1R-positive cells in the mPFC of both the young and aged mice was not changed by LPS. D, The bar graphs indicate the proportion of CD11b-positive cells out of 100 nuclei in the MPFC of naïve (open bar) and LPS-treated (closed bar) young and aged mice. The number of CD11b-positive cells in the young mPFC was increased by LPS; this effect did not occur in the aged mice. E, The bar graphs indicate the number of CD11b-positive cells that co-localized with GLP-1R in the mPFC of naive (open bars) and LPS-treated (closed bars) young and aged mice. The bars represent the means \pm SEM ( $n=9$ images from 3 mice).

\subsection{The Number of Double-Labelled CD11b and GLP-1R Positive Cell is Increased in the MPFC of Aged Mice}

In the present study, we found that GLP-1R is mainly expressed in pyramidal neurons in the CA1 region of the hippocampus. However, non-pyramidal neurons also highly express GLP-1R (Fig. 6B). Because it is unclear whether microglial cells express GLP-1R, we confirmed the immunoreactivity of GLP-1R and CD11b in the mPFC. The number of GLP-1R-positive cells in young $\mathrm{mPFC}$ was same level with aged $\mathrm{mPFC}$ (Fig. $8 \mathrm{~A}$, young naive: $34.9 \pm 4.5$, old naïve: $37.5 \pm 1.4, \mathrm{p}=0.3141, \mathrm{n}=9$ images from 3 mice, respectively). The number of CD11b-positive cells in the aged mice was significantly larger than in the young mice (Fig. 8A, $\mathrm{B}$ and D, young: $50.3 \pm 7.4$; aged: $71.7 \pm 5.9, \mathrm{p}=0.0386, \mathrm{n}=9$ images from 3 mice, respectively). In the LPS treated young $\mathrm{mPFC}$, the immunoreactivity of GLP-1R in $\mathrm{mPFC}$ was not altered by LPS (Fig. 8A, B and C, naive: $50.3 \pm 7.4$; LPS: 37.9 $\pm 6.2, \mathrm{p}=0.3671, \mathrm{n}=9$ images from 3 mice, respectively), although $\mathrm{CD} 11 \mathrm{~b}$ positive cell levels in the $\mathrm{mPFC}$ were 
significantly increased by LPS (Fig. 8A, B and D, naive: 50.3 \pm 7.4 ; LPS: $73.0 \pm 7.6, \mathrm{p}=0.3671, \mathrm{n}=9$ images from 3 mice, respectively). Interestingly, we found that the GLP-1R was also highly expressed in CD11b positive cells in mPFC of both young and old mice and not only expressed in neurons (Fig. $8 \mathrm{~A}$ and $\mathrm{B}$ ). Moreover, we found that the number of CD11b-positive cells that co-localized with GLP-1R in the $\mathrm{mPFC}$ is increased by LPS. (Fig. $8 \mathrm{~A}, \mathrm{~B}$ and $\mathrm{E}$, naive: $11.6 \pm$ 1.6; LPS: $31.1 \pm 8.5, \mathrm{p}=0.0389, \mathrm{n}=9$ images from 3 mice, respectively). As shown in Fig. 7, the expression level of $\mathrm{CD} 11 \mathrm{~b}$ in aged $\mathrm{mPFC}$ were already reached and LPS did not altered the number of CD11b positive cells (Fig. 8A, B and D, naïve old: $71.8 \pm 5.9$; LPS: $70.5 \pm 4.8, \mathrm{p}=0.4442, \mathrm{n}=9$ images from 3 mice, respectively). In the aged $\mathrm{mPFC}$, the number of CD11b positive cell co-localized with GLP-1R was also not altered by LPS (Fig. 8A, B and E, naïve old: $25.2 \pm$ 2.6; LPS: $29.2 \pm 6.2, \mathrm{p}=0.3058, \mathrm{n}=9$ images from 3 mice, respectively). These results indicate that the GLP-1R is also highly expressed in activated microglial cells and not only in the neurons in aged $\mathrm{mPFC}$ and the number of many increased CD11b-positive cells co-localized the GLP-1R in either immuno-activation and aging in the mPFC.

\subsection{Aged Mice are Impaired in Spatial Learning in the Water Maze}

We previously demonstrated that the GLP-1 receptor

A Acquisition phase in the water maze

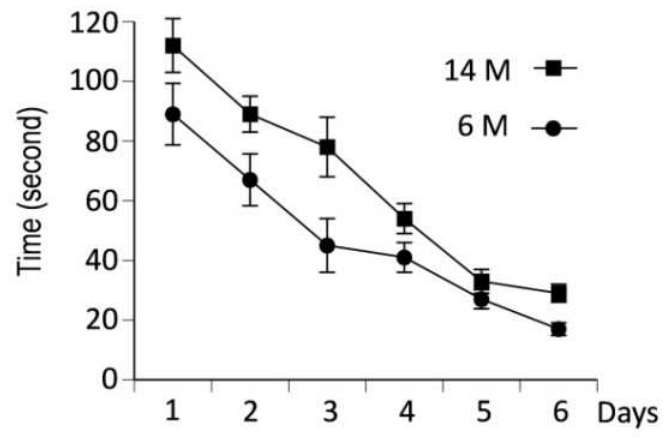

C

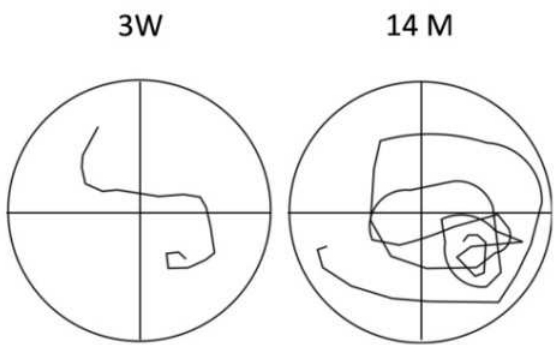

Figure 9. Aged mice are impaired in spatial learning in the water maze knockout (Glp1r(-/-)) mice were impaired in the acquisition phase of a water maze task [17]. Moreover, Glp1r gene transfer restored the learning deficit in GLP-1R-deficient mice [18]. Therefore, there is a possibility that the age-related decline of GLP-1 production in mPFC which lack the GLP-1R stimulation is contributing to the age-related cognitive decline. However, although there are many studies demonstrating that show age-related cognitive decline using aged mice [40-44], many of aged tested mice were over the 18 months old. In contrast to these, in the present study, we found that the GLP-1 expression level in $\mathrm{mPFC}$ of 14 month old mice was already significantly down-regulated compared with 6 months old mice. Therefore, we tested whether the 14 months old mice show an impairment in cognitive performance using a memory task in which mPFC function is involved [45, 46]. As we expected, 6 months old mice learned the water maze task faster in the acquisition phase compared to 14 month old mice (two-way ANOVA: group (14 months old) effect $p<0.005$, and time effect, $\mathrm{p}<0.01$, Fig. 9A). In the recall probe test without the platform, 6 months old mice remembered the location of the platform significantly better and spent more time in the pool quadrant that used to contain the platform which is compared with 14 months old mice (Fig. 9B, p<0.05), indicating that the age-related cognitive decline has already occurred in 14 months old mice.

\section{B Time spent in the target quadrant}

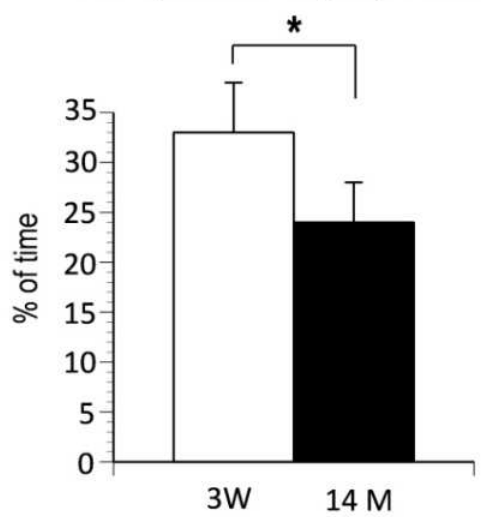

A, Six months old mice learned the water maze task faster in the acquisition phase compared to 16 month old mice ( $p<0.005$, and time effect $\mathrm{p}<0.01$ ). B, In the recall probe test without the platform, young mice remembered the location of the platform better and spent more time in the pool quadrant that used to contain the platform $(\mathrm{p}<0.05)$, see $\mathrm{C}$, Sample swim tracks of animals are shown in $1 \mathrm{C}$. All groups $\mathrm{n}=10$. 


\section{Discussion}

In the present study, we demonstrated that GLP-1 is decreased in the aged $\mathrm{mPFC}$ but not in the hippocampus or NTS. However, the normal protein level of GLP-1R is preserved in the mPFC as well as in the hippocampus of aged mice. The principal finding in this study is that the protein levels of GLP-1 and proglucagon in the $\mathrm{mPFC}$ are decreased in aged mice even in the absence of $A \beta$ toxicity. We previously suggested that exendin- 4 promotes the up-regulation of the membrane GluR1 subunit in both normal and $\mathrm{A} \beta$ oligomer-treated mice; thus, treatment with a GLP-1 analogue could carry a specific benefit for rescuing and ameliorating the age-related mPFC-dependent decline of cognitive functions.

Age-related changes in cognition, motivation, motor performance, and prefrontal immune gene expression were highly correlated [47]. In particular, CD11b-positive cells in the $\mathrm{mPFC}$ of aged mice show many changes in immunity-related characteristics [47]. In the present study, in contrast to the decrease in GLP-1 immunoreactivity observed in the $\mathrm{mPFC}$ of aged mice, the immunoreactivity rate of $\mathrm{CD} 11 \mathrm{~b}$ was higher in the mPFC of aged mice. Interestingly, in normal older adults, the aging-specific atrophy of certain cortical regions relates to cognitive performance, while in $\mathrm{AD}$ patients, atrophy in $\mathrm{AD}$-specific regions relates to cognitive performance [29]. Therefore, age-related cognitive decline is associated with microglial cell activity in the mPFC. Additionally, aging in mammals is characterized by a metabolic decline associated with obesity, altered body fat distribution, and insulin resistance [48]. In particular, increases in insulin resistance are associated with cognitive decline and an increased risk of $\mathrm{AD}$ [49]. It has been suggested that insulin-resistant conditions reduce the central mRNA expression of proglucagon [35]. GLP-1 signaling in the central nervous system (CNS) is an essential component of metabolic responses to hyperglycemia [50] and improves femoral artery blood flow and insulin sensitivity [51]. Moreover, liraglutide, a novel glucagon-like peptide 1 (GLP-1) analogue, ameliorates aberrant insulin receptor localization [52]. Exendin-4 and liraglutide also ameliorate Alzheimer's disease pathology and aid in restoring normal brain insulin responsiveness and cognitive function in preclinical tests $[13,53]$.

The increased inflammatory profile of the CNS with age is associated with microglial priming. This effect results in the increased expression of inflammatory markers including major histocompatibility complex (MHC) II and complement receptor 3 (CD11b) in the aged brain [54]. Many of these markers are present specifically on the microglia of the aged brain [55]. Interestingly, food restriction reduces the age-associated microglial activation in most subregions [56]. In the present study, the LPS-increased immunoreactivity of CD11b was heightened in young mice. However, CD11b immunoreactivity was higher in the $\mathrm{mPFC}$ of the aged mice, which did not show a significant sensitivity to LPS. Moreover, most of the GLP-1 immunoreactivity in the mPFC was co-localized with $\mathrm{CD} 11 \mathrm{~b}$ in both young and aged mice. Animals with high-fat diet-induced obesity (DIO) and insulin resistance have a significantly increased $\mathrm{IgG}$ accumulation in hypothalamic microglia [57]. The $\mathrm{db} / \mathrm{db}$ mice with insulin resistance have a lower threshold for the release of pro-inflammatory cytokines in response to LPS. Taken together, the combined effects of lower GLP-1 and the hyperactivity of microglia (resulting from higher insulin resistance in the brain) could be associated with cognitive decline. $A \beta$ itself is pro-inflammatory and activates microglia [58]. In the present study, we found that the GLP-1R is highly expressed in pyramidal neurons of areas CA1 and CA3 and in granule cells in dentate gyrus of the hippocampus. However, the GLP-1R is also highly expressed in microglial cells which are $\mathrm{CD} 11 \mathrm{~b}$ positive. Although the expression level of GLP-1R is not altered in the aged mPFC compared with young $\mathrm{mPFC}$, the number of CD11b-positive cells that co-localized with GLP-1R in the mPFC is increased in either immune-activation and aging. It has been reported that the autocrine action of GLP-1 in gut L cells, a GLP-1 producing cell enhanced GLP-1 secretion [59]. Therefore, reduced in GLP-1 production in aged $\mathrm{mPFC}$ could be negatively regulated by the autocrine system in microglial cells. Moreover, because GLP-1 receptor stimulation reduces amyloid- $\beta$ peptide accumulation and cytotoxicity [60], not only the normal aging but $\mathrm{mPFC}$ in $\mathrm{AD}$ patients could also be affected by the age-related decline of GLP-1 production. Indeed, a higher level of CD11b positive cells is observed in AD brains, and anti-inflammatory responses can reduce brain $\mathrm{A} \beta$ levels, amyloid plaque burden, and microglial activation in an animal model of Alzheimer's disease [61-63]. However, because the protein and immunoreactivity level of GLP-1 in hippocampus was preserved in aged mice, it is not unlikely that the increased CD11b cause the negative regulation of the GLP-1 production in microglial cells in brain. Activated microglia release pro-inflammatory cytokines such as TNF- $\alpha$, which downregulate GLP-1 signaling and gene expression [53]. In addition to these properties of GLP-1, we had demonstrated in a previous study that the expression of mature ADAM10, an $\alpha$-secretase of APP on the plasma membrane, was increased in exendin-4-treated mice [14]. Increased secretion at the $\alpha$-site of APP inhibits the accumulation of $A \beta$. Therefore, because the GLP-1R expression level is preserved even in aged $\mathrm{mPFC}$, treatment with GLP-1 analogues and GLP-1R stimulation may enhance GLP-1 expression and could rescue from the accumulation of $A \beta$ and microglial activation which are observed in $\mathrm{AD}$ patients $[63,64]$.

In the present study, an age-related decrease in GLP-1 was observed in the mPFC but neither in the hippocampus nor NTS. A previous study demonstrated that both older and younger adults showed a hippocampal blood flow increase in association with the recollection of memorized words. In contrast, younger but not older adults showed a bilateral blood flow increase in the anterior prefrontal cortex during retrieval attempts [65]. Additionally, a certain synaptic aging effect in 
the mPFC is different from that in the hippocampus. Particularly, this difference is associated with the extensive loss of axospinous synapses in the $\mathrm{mPFC}$ or the synaptic stability level in the hippocampus [66]. These differences in processes such as blood flow levels or the synaptic loss between the mPFC and the hippocampus could affect the activity of GLP-1 produced in aged mPFC. However, it remains unclear why the hippocampus and the PFC of young and aged subjects have differing GLP-1 production rates.

In a previous report, reduced choline acetyltransferase in several brain areas was observed in patients with AD. This effect was due to the action of current $\mathrm{AD}$ therapies that mainly targeted the increase in acetyl cholinesterase (AChE) in the brain. Memantine, a well-tolerated N-methyl-D-aspartate glutamate receptor antagonist, has recently been widely used for protecting against neuronal death from $A \beta$ toxicity. In particular, combined treatment with memantine and donepezil is effective to some degree in AD patients [67]. However, the drugs only mask the symptoms and do not prevent further degeneration, and neurodegeneration in AD patients is in reality not limited to a specific neurotransmitter system. Many laboratories have demonstrated that the use of growth factors and GPCR stimulation has some effectiveness in different stages of $A D$ $[19,68]$. Interestingly, the sequential cleavage of APP by the $\alpha$, $\beta$ and $\gamma$-secretases, which are regulated by GPCRs, determines the extent of $A \beta$ peptide generation [19]. Activating a different Gas protein-coupled receptor as a potential $\mathrm{AD}$ treatment has also been reported [21, 22]. The GLP-1R is also a Gas protein-coupled receptor. The growth factor Pituitary Adenylate Cyclase Activating Polypeptide (PACAP) is also decreased in an age-dependent manner in brain microvessels [69]. In comparison with other growth factors, a main advantage of the GLP-1 analogues liraglutide, lixisenatide and exenatide is that they can cross the blood-brain barrier and can be injected peripherally $[70,71]$ and they are already on the market as a T2DM treatment (trade names Victoza and Byetta). It has been shown that they improve memory and synaptic plasticity, and have a neuroprotective effect against amyloid oligomers, reduce the numbers of amyloid plaques and inflammation response, and increase neurogenesis translate in animals, if these effects are exerted in human, GLP-1 analogs are a promising new treatment modality for Alzheimer's disease [72].

We have shown that 14 months old mice are impaired in spatial cognitive learning. Of course, from our result, we cannot exclude the possibility that other factors contribute to the impairment of cognitive performance in 14 months old mice, because there are numerous factors and signaling pathways being altered in aging and are most likely involved in the deficient of cognitive learning are reported. However, as we have also suggested in the previous study, liraglutide, a long-lasting GLP-1 analog prevented memory impairments in object recognition and water maze tasks and synaptic plasticity in both early phase and aged (14 months old) mice that are an APP/PS1 Alzheimer mouse model [73, 74]. Therefore, the decline of GLP-1 expression in mPFC of 14 months old mice could contribute to the impairment of cognitive performance, because the decline of GLP-1 production cannot maintain the normal level of GLP-1R stimulation in aged mice and could results in the induction of cognitive impairment as shown in Glp1r(-/-)) mice which were impaired in the cognitive memory task [17]. Taken together, in view of the age-related decline of GLP-1 expression in $\mathrm{mPFC}$ and the protective effects of GLP-1R activation, the use of GLP-1 analogues is a promising approach for people with age-related cognitive decline in normal aging and in $\mathrm{AD}$ patients.

\section{Conclusion}

In conclusion, GLP-1 is significantly decreased in the aged $\mathrm{mPFC}$, but GLP-1R is preserved, indicating that the treatment with a GLP-1 analogue is beneficial for ameliorating the decrease in age-related mPFC-dependent decline of cognitive functions. Moreover, exendin-4 promotes the up-regulation of the membrane GluR1 subunit in the neocortex [14], indicating that exendin-4 may facilitate neuronal synaptic plasticity in the neocortex. Moreover, we previously demonstrated that exendin-4 also promotes the up-regulation of the mature form of ADAM10 at the plasma membrane. GLP-1 receptor stimulation has precipitated the reduction in amyloid- $\beta$ peptide accumulation and cytotoxicity [60]. These properties of GLP-1R indicate that the use of GLP-1 analogues as a treatment for $\mathrm{AD}$ patients is potentially one of the most beneficial approaches among current candidates under development.

\section{Acknowledgments}

We thank Ms. Natsuki Kurosawa and Mr. Ko Shimizu for help with a part of tissue preparation for the immunofluorescence. This work was supported partly by a Grant-in-Aid for Scientific Research (C) from the Ministry of Education, Culture, Sports, Science, and Technology (Grant Number: 25430070) and Grants for Research in the School of Pharmaceutical Science, Ohu University to K. Seki.

\section{Abbreviations}

AMPA, $\alpha$-Amino-3-hydroxy-5-methyl-4-isoxazolepropionic acid;

cAMP, cyclic 3'-5'-cyclic adenosine monophosphate;

ADAM10, a disintegrin and metalloproteinase

domain-containing protein 10 ;

SDS, sodium dodecyl sulfate;

PVDF, polyvinylidene difluoride;

BSA, bovine serum albumin;

ECL, enhanced chemiluminescence;

PKA, protein kinase A;

Gas protein, Gs alpha subunit protein; EDTA; ethylenediaminetetraacetic acid; EGTA, ethylene glycol tetra-acetic acid; PMSF, phenylmethylsulfonyl fluoride. 


\section{References}

[1] de la Monte SM. Brain insulin resistance and deficiency as therapeutic targets in Alzheimer's disease. Current Alzheimer research 2012; 9:35-66.

[2] Holscher C. Diabetes as a risk factor for Alzheimer's disease: insulin signalling impairment in the brain as an alternative model of Alzheimer's disease. Biochemical Society transactions 2011; 39:891-7.

[3] Talbot K, Wang HY, Kazi H, Han LY, Bakshi KP, Stucky A, et al. Demonstrated brain insulin resistance in Alzheimer's disease patients is associated with IGF-1 resistance, IRS-1 dysregulation, and cognitive decline. The Journal of clinical investigation 2012; 122:1316-38.

[4] de la Monte SM. Contributions of brain insulin resistance and deficiency in amyloid-related neurodegeneration in Alzheimer's disease. Drugs 2012; 72:49-66.

[5] Freiherr J, Hallschmid M, Frey WH, 2nd, Brunner YF, Chapman $\mathrm{CD}$, Holscher $\mathrm{C}$, et al. Intranasal insulin as a treatment for Alzheimer's disease: a review of basic research and clinical evidence. CNS drugs 2013; 27:505-14.

[6] Yang Y, Zhang J, Ma D, Zhang M, Hu S, Shao S, et al. Subcutaneous administration of liraglutide ameliorates Alzheimer-associated tau hyperphosphorylation in rats with type 2 diabetes. Journal of Alzheimer's disease: JAD 2013; 37:637-48.

[7] Femminella GD, Edison P. Evaluation of neuroprotective effect of glucagon-like peptide 1 analogs using neuroimaging. Alzheimer's \& dementia: the journal of the Alzheimer's Association 2014; 10:S55-61.

[8] Holscher C. Potential role of glucagon-like peptide-1 (GLP-1) in neuroprotection. CNS drugs 2012; 26:871-82.

[9] Kosaraju J, Murthy V, Khatwal RB, Dubala A, Chinni S, Muthureddy Nataraj SK, et al. Vildagliptin: an anti-diabetes agent ameliorates cognitive deficits and pathology observed in streptozotocin-induced Alzheimer's disease. The Journal of pharmacy and pharmacology 2013; 65:1773-84.

[10] Mossello E, Ballini E, Boncinelli M, Monami M, Lonetto G, Mello AM, et al. Glucagon-like peptide-1, diabetes, and cognitive decline: possible pathophysiological links and therapeutic opportunities. Experimental diabetes research 2011; 2011:281674.

[11] Holscher C. Incretin analogues that have been developed to treat type 2 diabetes hold promise as a novel treatment strategy for Alzheimer's disease. Recent patents on CNS drug discovery 2010; 5:109-17.

[12] Holscher C. The incretin hormones glucagonlike peptide 1 and glucose-dependent insulinotropic polypeptide are neuroprotective in mouse models of Alzheimer's disease. Alzheimer's \& dementia: the journal of the Alzheimer's Association 2014; 10:S47-54.

[13] Talbot K. Brain insulin resistance in Alzheimer's disease and its potential treatment with GLP-1 analogs. Neurodegenerative disease management 2014; 4:31-40.

[14] Ohtake N, Saito M, Eto M, Seki K. Exendin-4 promotes the membrane trafficking of the AMPA receptor GluR1 subunit and ADAM10 in the mouse neocortex. Regulatory peptides 2014; 190-191:1-11.

[15] McClean PL, Gault VA, Harriott P, Holscher C. Glucagon-like peptide-1 analogues enhance synaptic plasticity in the brain: a link between diabetes and Alzheimer's disease. European journal of pharmacology 2010; 630:158-62.

[16] McClean P, Parthsarathy V, Faivre E, Hölscher C. The diabetes drug Liraglutide prevents degenerative processes in a mouse model of Alzheimer's disease. J Neurosci 2011; 31:6587-94.

[17] Abbas T, Faivre E, Holscher C. Impairment of synaptic plasticity and memory formation in GLP-1 receptor KO mice: Interaction between type 2 diabetes and Alzheimer's disease. Behavioural brain research 2009; 205:265-71.

[18] During MJ, Cao L, Zuzga DS, Francis JS, Fitzsimons HL, Jiao $\mathrm{X}$, et al. Glucagon-like peptide-1 receptor is involved in learning and neuroprotection. Nature medicine 2003; 9:1173-9.

[19] Thathiah A, De Strooper B. The role of G protein-coupled receptors in the pathology of Alzheimer's disease. Nature reviews Neuroscience 2011; 12:73-87.

[20] Hallbrink M, Holmqvist T, Olsson M, Ostenson CG, Efendic S, Langel U. Different domains in the third intracellular loop of the GLP-1 receptor are responsible for Galpha(s) and Galpha(i)/Galpha(o) activation. Biochimica et biophysica acta 2001; 1546:79-86.

[21] Pimenova AA, Thathiah A, De Strooper B, Tesseur I. Regulation of amyloid precursor protein processing by serotonin signaling. PloS one 2014; 9:e87014.

[22] Kojro E, Postina R, Buro C, Meiringer C, Gehrig-Burger K, Fahrenholz F. The neuropeptide PACAP promotes the alpha-secretase pathway for processing the Alzheimer amyloid precursor protein. FASEB journal: official publication of the Federation of American Societies for Experimental Biology 2006;20:512-4.

[23] Perry T, Holloway HW, Weerasuriya A, Mouton PR, Duffy K, Mattison JA, et al. Evidence of GLP-1-mediated neuroprotection in an animal model of pyridoxine-induced peripheral sensory neuropathy. Experimental neurology 2007; 203:293-301.

[24] Dore S, Kar S, Quirion R. Insulin-like growth factor I protects and rescues hippocampal neurons against beta-amyloid- and human amylin-induced toxicity. Proceedings of the National Academy of Sciences of the United States of America 1997; 94:4772-7.

[25] Signore AP, Zhang F, Weng Z, Gao Y, Chen J. Leptin neuroprotection in the CNS: mechanisms and therapeutic potentials. Journal of neurochemistry 2008; 106:1977-90.

[26] Bradbury J. Hope for AD with NGF gene-therapy trial. Lancet neurology 2005; 4:335.

[27] Nagahara AH, Merrill DA, Coppola G, Tsukada S, Schroeder BE, Shaked GM, et al. Neuroprotective effects of brain-derived neurotrophic factor in rodent and primate models of Alzheimer's disease. Nature medicine 2009; 15:331-7.

[28] Oh H, Madison C, Haight TJ, Markley C, Jagust WJ. Effects of age and beta-amyloid on cognitive changes in normal elderly people. Neurobiology of aging 2012; 33:2746-55. 
[29] Bakkour A, Morris JC, Wolk DA, Dickerson BC. The effects of aging and Alzheimer's disease on cerebral cortical anatomy: specificity and differential relationships with cognition. NeuroImage 2013; 76:332-44.

[30] Puddu A, Sanguineti R, Montecucco F, Viviani GL. Retinal pigment epithelial cells express a functional receptor for glucagon-like peptide-1 (GLP-1). Mediators of inflammation 2013; 2013:975032.

[31] Hamilton A, Holscher C. Receptors for the incretin glucagon-like peptide-1 are expressed on neurons in the central nervous system. Neuroreport 2009; 20:1161-6.

[32] Renner E, Puskas N, Dobolyi A, Palkovits M. Glucagon-like peptide-1 of brainstem origin activates dorsomedial hypothalamic neurons in satiated rats. Peptides 2012; 35:14-22.

[33] Gier B, Butler PC, Lai CK, Kirakossian D, DeNicola MM, Yeh MW. Glucagon like peptide-1 receptor expression in the human thyroid gland. The Journal of clinical endocrinology and metabolism 2012; 97:121-31.

[34] Trapp S, Richards JE. The gut hormone glucagon-like peptide-1 produced in brain: is this physiologically relevant? Current opinion in pharmacology 2013; 13:964-9.

[35] Kappe C, Tracy LM, Patrone C, Iverfeldt K, Sjoholm A. GLP-1 secretion by microglial cells and decreased CNS expression in obesity. Journal of neuroinflammation 2012; 9:276.

[36] Iwai T, Ito S, Tanimitsu K, Udagawa S, Oka J. Glucagon-like peptide-1 inhibits LPS-induced IL-1beta production in cultured rat astrocytes. Neuroscience research 2006; 55:352-60.

[37] Merchenthaler I, Lane M, Shughrue P. Distribution of pre-pro-glucagon and glucagon-like peptide-1 receptor messenger RNAs in the rat central nervous system. The Journal of comparative neurology 1999; 403:261-80.

[38] Norden DM, Godbout JP. Review: microglia of the aged brain: primed to be activated and resistant to regulation. Neuropathology and applied neurobiology 2013; 39:19-34.

[39] Hart AD, Wyttenbach A, Perry VH, Teeling JL. Age related changes in microglial phenotype vary between CNS regions: grey versus white matter differences. Brain, behavior, and immunity 2012; 26:754-65.

[40] Cao L, Wang F, Yang QG, Jiang W, Wang C, Chen YP, et al. Reduced thyroid hormones with increased hippocampal SNAP-25 and Munc18-1 might involve cognitive impairment during aging. Behavioural brain research 2012; 229:131-7.

[41] Nichol KE, Parachikova AI, Cotman CW. Three weeks of running wheel exposure improves cognitive performance in the aged Tg2576 mouse. Behavioural brain research 2007;184:124-32.

[42] Murphy GG, Rahnama NP, Silva AJ. Investigation of age-related cognitive decline using mice as a model system: behavioral correlates. The American journal of geriatric psychiatry: official journal of the American Association for Geriatric Psychiatry 2006; 14:1004-11.

[43] Carrie I, Debray M, Bourre JM, Frances H. Age-induced cognitive alterations in OF1 mice. Physiology \& behavior 1999; 66:651-6.

[44] Stoll S, Hafner U, Pohl O, Muller WE. Age-related memory decline and longevity under treatment with selegiline. Life sciences 1994; 55:2155-63.
[45] Jo YS, Park EH, Kim IH, Park SK, Kim H, Kim HT, et al. The medial prefrontal cortex is involved in spatial memory retrieval under partial-cue conditions. J Neurosci 2007; 27:13567-78.

[46] Magnusson KR, Scruggs B, Zhao X, Hammersmark R. Age-related declines in a two-day reference memory task are associated with changes in NMDA receptor subunits in mice. BMC neuroscience 2007; 8:43.

[47] Bordner KA, Kitchen RR, Carlyle B, George ED, Mahajan MC, Mane SM, et al. Parallel declines in cognition, motivation, and locomotion in aging mice: association with immune gene upregulation in the medial prefrontal cortex. Experimental gerontology 2011; 46:643-59.

[48] Enns LC, Morton JF, Mangalindan RS, McKnight GS, Schwartz MW, Kaeberlein MR, et al. Attenuation of age-related metabolic dysfunction in mice with a targeted disruption of the Cbeta subunit of protein kinase A. The journals of gerontology Series A, Biological sciences and medical sciences 2009; 64:1221-31.

[49] Morris JK, Vidoni ED, Honea RA, Burns JM. Impaired glycemia increases disease progression in mild cognitive impairment. Neurobiology of aging 2014; 35:585-9.

[50] Cabou C, Campistron G, Marsollier N, Leloup C, Cruciani-Guglielmacci C, Penicaud L, et al. Brain glucagon-like peptide-1 regulates arterial blood flow, heart rate, and insulin sensitivity. Diabetes 2008; 57:2577-87.

[51] Cabou C, Vachoux C, Campistron G, Drucker DJ, Burcelin R. Brain GLP-1 signaling regulates femoral artery blood flow and insulin sensitivity through hypothalamic PKC-delta. Diabetes 2011; 60:2245-56.

[52] Long-Smith CM, Manning S, McClean PL, Coakley MF, O'Halloran DJ, Holscher C, et al. The diabetes drug liraglutide ameliorates aberrant insulin receptor localisation and signalling in parallel with decreasing both amyloid-beta plaque and glial pathology in a mouse model of Alzheimer's disease. Neuromolecular medicine 2013; 15:102-14.

[53] Bomfim TR, Forny-Germano L, Sathler LB, Brito-Moreira J, Houzel JC, Decker H, et al. An anti-diabetes agent protects the mouse brain from defective insulin signaling caused by Alzheimer's disease- associated Abeta oligomers. The Journal of clinical investigation 2012; 122:1339-53.

[54] Perry VH, Matyszak MK, Fearn S. Altered antigen expression of microglia in the aged rodent CNS. Glia 1993; 7:60-7.

[55] Henry CJ, Huang Y, Wynne AM, Godbout JP. Peripheral lipopolysaccharide (LPS) challenge promotes microglial hyperactivity in aged mice that is associated with exaggerated induction of both pro-inflammatory IL-1beta and anti-inflammatory IL-10 cytokines. Brain, behavior, and immunity 2009; 23:309-17.

[56] Morgan TE, Xie Z, Goldsmith S, Yoshida T, Lanzrein AS, Stone $\mathrm{D}$, et al. The mosaic of brain glial hyperactivity during normal ageing and its attenuation by food restriction. Neuroscience 1999; 89:687-99.

[57] Yi CX, Tschop MH, Woods SC, Hofmann SM. High-fat-diet exposure induces IgG accumulation in hypothalamic microglia. Disease models \& mechanisms 2012; 5:686-90.

[58] Fan R, Tenner AJ. Differential regulation of Abeta42-induced neuronal C1q synthesis and microglial activation. Journal of neuroinflammation $2005 ; 2: 1$. 
[59] Kappe C, Zhang Q, Holst JJ, Nystrom T, Sjoholm A. Evidence for paracrine/autocrine regulation of GLP-1-producing cells. American journal of physiology Cell physiology 2013; 305:C1041-9.

[60] Li Y, Duffy KB, Ottinger MA, Ray B, Bailey JA, Holloway HW, et al. GLP-1 receptor stimulation reduces amyloid-beta peptide accumulation and cytotoxicity in cellular and animal models of Alzheimer's disease. Journal of Alzheimer's disease: JAD 2010; 19:1205-19.

[61] Scali C, Prosperi C, Bracco L, Piccini C, Baronti R, Ginestroni $A$, et al. Neutrophils CD11b and fibroblasts PGE(2) are elevated in Alzheimer's disease. Neurobiology of aging 2002; 23:523-30.

[62] Yan Q, Zhang J, Liu H, Babu-Khan S, Vassar R, Biere AL, et al. Anti-inflammatory drug therapy alters beta-amyloid processing and deposition in an animal model of Alzheimer's disease. J Neurosci 2003; 23:7504-9.

[63] van Groen T, Miettinen P, Kadish I. Transgenic AD model mice, effects of potential anti-AD treatments on inflammation, and pathology. Journal of Alzheimer's disease: JAD 2011; 24:301-13.

[64] Jimenez S, Baglietto-Vargas D, Caballero C, Moreno-Gonzalez I, Torres M, Sanchez-Varo R, et al. Inflammatory response in the hippocampus of PS1M146L/APP751SL mouse model of Alzheimer's disease: age-dependent switch in the microglial phenotype from alternative to classic. J Neurosci 2008; 28:11650-61.

[65] Schacter DL, Savage CR, Alpert NM, Rauch SL, Albert MS. The role of hippocampus and frontal cortex in age-related memory changes: a PET study. Neuroreport 1996; 7:1165-9.

[66] Morrison JH, Baxter MG. The ageing cortical synapse: hallmarks and implications for cognitive decline. Nature reviews Neuroscience 2012; 13:240-50.
[67] Araki T, Wake R, Miyaoka T, Kawakami K, Nagahama M, Furuya $\mathrm{M}$, et al. The effects of combine treatment of memantine and donepezil on Alzheimer's Disease patients and its relationship with cerebral blood flow in the prefrontal area. International journal of geriatric psychiatry 2014.

[68] Holscher C. The incretin hormones glucagonlike peptide 1 and glucose-dependent insulinotropic polypeptide are neuroprotective in mouse models of Alzheimer's disease. Alzheimer's \& dementia: the journal of the Alzheimer's Association 2014; 10:S47-S54.

[69] Tripathy D, Sanchez A, Yin X, Martinez J, Grammas P. Age-related decrease in cerebrovascular-derived neuroprotective proteins: effect of acetaminophen. Microvascular research 2012; 84:278-85.

[70] Kastin AJ, Akerstrom V. Entry of exendin-4 into brain is rapid but may be limited at high doses. International journal of obesity and related metabolic disorders: journal of the International Association for the Study of Obesity 2003; 27:313-8.

[71] Hunter K, Holscher C. Drugs developed to treat diabetes, liraglutide and lixisenatide, cross the blood brain barrier and enhance neurogenesis. BMC neuroscience 2012;13:33-8.

[72] Holscher C. Insulin, incretins and other growth factors as potential novel treatments for Alzheimer's and Parkinson's diseases. Biochemical Society transactions 2014;42:593-9.

[73] McClean PL, Parthsarathy V, Faivre E, Holscher C. The diabetes drug liraglutide prevents degenerative processes in a mouse model of Alzheimer's disease. J Neurosci 2011; 31:6587-94.

[74] McClean PL, Holscher C. Liraglutide can reverse memory impairment, synaptic loss and reduce plaque load in aged APP/PS1 mice, a model of Alzheimer's disease. Neuropharmacology 2014; 76 Pt A:57-67. 